\title{
Application of nanostructured lipid carriers: the prolonged protective effects for sesamol in in vitro and in vivo models of ischemic stroke via activation of PI3K signalling pathway
}

\author{
Parichehr Hassanzadeh ${ }^{1}$, Fatemeh Atyabi ${ }^{1,2^{*}}$, Rassoul Dinarvand ${ }^{1,2}$, Ahmad-Reza Dehpour ${ }^{3}$,
} Morteza Azhdarzadeh ${ }^{1}$ and Meshkat Dinarvand ${ }^{1}$

\begin{abstract}
Background: Treatment of the ischemic stroke has remained a major healthcare challenge. The phenolic compound, sesamol, has shown promising antioxidant and neuroprotective effects, however, fast clearance may negatively affect its efficiency. This, prompted us to incorporate sesamol into the nanostructured lipid carriers (S-NLCS) and evaluate its therapeutic potential in in vitro and in vivo models of ischemic stroke.

Methods: S-NLCs formulations were prepared by high-pressure homogenization followed by physicochemical characterization, evaluation of the bioactivity of the optimal formulation in oxygen-glucose deprivation (OGD) and global cerebral ischemia/reperfusion (I/R) injury and implication of phosphatidylinositol 3-kinase (PI3K) pathway in this regard. Two- or three-way ANOVA, Mann-Whitney $U$ test, and Student's t-test were used for data analysis.

Results: Formation of S-NLCs which exhibited a controlled release profile, was confirmed by scanning electron microscope and differential scanning calorimetry. 1- and 8-h OGD followed by $24 \mathrm{~h}$ re-oxygenation significantly reduced PC12 cell viability, increased lactate dehydrogenase activity and the number of condensed nuclei, and induced oxidative stress as revealed by increased malondialdehyde level and decreased glutathione content and superoxide dismutase and catalase activities. Sesamol (80 and $100 \mu \mathrm{M})$ reduced the cytotoxicity, oxidative stress, and cellular damage only after 1-h OGD, while, S-NLCs (containing 80 and $100 \mu \mathrm{M}$ of sesamol) were effective at both time points. Intravenous injections of S-NLCs (20 and $25 \mathrm{mg} / \mathrm{kg}$ ) into rats markedly attenuated I/R-induced neurobehavioural deficits, cellular damage, and oxidative stress, while, free sesamol failed. Pre-treatment with PI3K inhibitor, LY294002, abolished the protective effects against $O G D$ or $\mathrm{l} / \mathrm{R}$.
\end{abstract}

Conclusions: S-NLCs improve the pharmacological profile of sesamol and provide longer lasting protective effects for this phenolic phytochemical. This nanoformulation by activating PI3K pathway may serve as a promising candidate for neuroprotection against the cerebral stroke or other neurodegenerative disorders.

Keywords: Sesamol, Nanostructured lipid carriers, Ischemic stroke, Phosphoinositide 3-kinase, PC12 cells, Rat

\footnotetext{
* Correspondence: atyabifa@tums.ac.ir

${ }^{1}$ Nanotechnology Research Center, Faculty of Pharmacy, Tehran University of

Medical Sciences, Tehran, Iran

${ }^{2}$ Department of Pharmaceutics, Faculty of Pharmacy, Tehran University of

Medical Sciences, Tehran, Iran

Full list of author information is available at the end of the article
} 


\section{Background}

Ischemic stroke is one of the major causes of disability and death worldwide $[1,2]$. Following the severe reduction or interruption of blood flow and oxygen in the cerebral arteries, a sequence of events including the inflammation, oxidative stress, mitochondrial dysfunction, and excessive release of excitatory amino acids may result in the neuronal death [2-4]. Based on the brain's requirement to a continuous supply of oxygen and glucose, it is the most susceptible organ to the oxygenglucose deprivation and oxidative stress [5]. The limited efficiency of the currently available medications and their short therapeutic time windows [1], has provoked increasing research efforts to develop novel treatment strategies. During the last decade, antioxidant and neuroprotective effects of the phenolic compounds have been the focus of intense research. In this respect, sesamol, the major constituent of sesame seed oil (Sesamum indicum, Linn, Pedaliaceae) has attracted a growing interest due to its high safety profile and wide spectrum of pharmacological activities including the effects against the inflammation, oxidative stress, aging, and depression [6-9]. Moreover, sesamol has shown antithrombotic and neuroprotective properties [10-13] which might be of therapeutic value in the ischemic stroke. However, rapid elimination of sesamol $[14,15]$ may negatively affect its efficiency that necessitates the development of suitable drug delivery system to improve the stability and bioavailability of this phenolic compound. Over the last few decades, nanotechnology entities have been used to deliver compounds with poor solubility or short half-life [16-23]. There are reports demonstrating the efficiency of nanomaterials for detection or treatment of stroke [24-26]. In recent years, lipid-based colloidal drug delivery systems including the solid lipid nanoparticles (SLNs) and nanostructured lipid carriers (NLCs) as the alternative carrier systems to the liposomes, emulsions, and polymeric nanoparticles have attracted considerable attention. These biocompatible carriers protect the encapsulated active ingredients against the enzymatic degradation and are suitable for targeted drug delivery or controlled release [27]. SLNs have shown advantages of scale-up feasibility, sterility, and protection of incorporated compounds against the degradation, however, the risk of gelation, limited drug-loading capacity, and the possibility of drug leakage during the storage [27-29] led to the development of NLCs, a binary mixture of liquid and solid lipids which provides an imperfect matrix structure. Indeed, NLCs are a smarter generation of drug carriers with high biocompatibility, stability, and drugloading capacity, prolonged drug residence in the target organ, and minimal drug expulsion during the storage [27, 30, 31]. This background prompted us to prepare sesamolloaded NLCs (S-NLCs) and evaluate the therapeutic potential of this nanoformulation in both in vitro and in vivo models of ischemic stroke. As a mechanistic approach, we looked at the role of phosphatidylinositol 3-kinase (PI3K) pathway which is critically involved in the cell proliferation and survival $[32,33]$.

\section{Methods \\ Materials}

Cell culture materials were all purchased from GIBCO/ Invitrogen, Germany. Cetyl palmitate and Tween 80 were provided by Merck (Darmstadt, Germany) and other chemicals or kits were purchased from Sigma Aldrich, Germany.

\section{Preparation of sesamol-loaded NLCs (S-NLCs)}

S-NLCs were prepared by high-pressure homogenization [34] with some modifications. Briefly, the lipid phase (cetyl palmitate and oleic acid; $85: 15$ or 70:30) was prepared at $75{ }^{\circ} \mathrm{C}$ and sesamol (3,4-methylenedioxyphenol) was added at $5,10,20,40$, or $100 \% \mathrm{w} / \mathrm{w}$. The aqueous phase was prepared at $75{ }^{\circ} \mathrm{C}$ by dispersing poloxamer 188 (0.5 or $1 \%, w /$ $v)$ and Tween $80(1$ or $2 \%, w / v)$ in double-distilled water and was subsequently added to the lipid phase under high-speed stirring (Ultra Turrax T25, IKA, Germany) at $8000 \mathrm{rpm}$ for $30 \mathrm{~s}$. The obtained pre-emulsion was subjected to high-pressure homogenization (Micron LAB 40, Germany) at 500 bar and $75{ }^{\circ} \mathrm{C}$ for ten cycles. For further size reduction, the emulsion was sonicated (Ultra sonic, tecno-Gaz Tecna 6, Italy) at 70\% amplitude for $2,4,10$, or $15 \mathrm{~min}$. Afterwards, the nanoemulsion was cooled down to room temperature and then lyophilized (Freeze Drier, Christ, Germany) and stored at $4{ }^{\circ} \mathrm{C}$. Blank NLCs were prepared by the same procedure.

\section{Characterization of S-NLCs}

Particle size, polydispersity index (PDI), and zeta potential (ZP)

NLCs dispersions were diluted by deionized water and the mean particle size, PDI, and ZP were analyzed at $25{ }^{\circ} \mathrm{C}$ by photon correlation spectroscopy (Zetasizer, Malvern Instruments, UK) $(n=6)$.

\section{Morphological assessment}

Scanning electron microscope (KYKY-EM3200, China) was used to evaluate the shape of nanoparticles.

Entrapment efficiency (EE) and drug loading capacity (DL) S-NLC dispersion was placed in the upper chamber of an Amicon $^{\odot}$ centrifugal filter and centrifuged at $1500 \mathrm{~g}$ for $30 \mathrm{~min}$. Then, the un-entrapped sesamol in the filtrate was analysed by high-performance liquid chromatography (HPLC) using Alliance 2695 system (Waters Corp, USA) with C18 column $(250 \times 4.6 \mathrm{~mm}, 5 \mu \mathrm{m})$ at room temperature. The mobile phase contained acetonitrile/ 
water/acetic acid (68:30:2, v/v) at flow rate of $1 \mathrm{ml} / \mathrm{min}$ and the sample injection volume was $50 \mu$ l. The limits of detection and quantification (LOD and LOQ) values were approximately 0.023 and $0.059 \mu \mathrm{g} / \mathrm{ml}$, respectively, and the inter- and intra-day coefficients of variations were within $\pm 5 \%$. EE\% and DL of S-NLCs were determined as follows:

$$
\begin{aligned}
& \mathrm{EE} \%=\frac{\text { Theamount of sesamol encapsulated in NLCs }}{\text { Total amount of sesamol }} \times 100 \\
& \mathrm{DL} \%=\frac{\text { Theamount of sesamol encapsulated in NLCs }}{\text { Total amount of NLCs }} \times 100
\end{aligned}
$$

\section{Differential scanning calorimetry (DSC)}

Thermal analysis of pure sesamol, cetyl palmitate, SNLCs, or blank NLCs was performed by DSC apparatus (Mettler-Toledo, Switzerland). Each sample was placed in an aluminum pan and heated in the range $10-240{ }^{\circ} \mathrm{C}$ $\left(10{ }^{\circ} \mathrm{C} / \mathrm{min}\right)$ under a nitrogen purge $(50 \mathrm{ml} / \mathrm{min})$. Each experiment was carried out in triplicate.

\section{In vitro release}

The release profile of sesamol form NLCs was evaluated by dialysis membrane method [35]. Briefly, $5 \mathrm{ml}$ of SNLC solution was transferred into a dialysis bag with a molecular weight cut-off of $12 \mathrm{KD}$ (Sigma laboratories, Osterode, Germany) which had been previously soaked in the release medium for $24 \mathrm{~h}$. The dialysis bag was sealed at both ends and immersed in the receptor compartment containing $250 \mathrm{ml}$ of phosphate-buffered saline (PBS, pH 7.4) in a shaking incubator (Heidolph Unimax 1010, Germany) at $37{ }^{\circ} \mathrm{C}$ and $100 \mathrm{rpm}$. At defined time intervals, $0.5-\mathrm{ml}$ samples were collected from the receptor medium, replaced with pre-warmed fresh PBS of an equal volume, and assayed for sesamol content by HPLC. The percentage of dose released was plotted against the time and sesamol solution served as control. Experiments were carried out in triplicate.

\section{Storage stability}

Freeze-dried samples were kept at $4{ }^{\circ} \mathrm{C}$. At defined time intervals $(0,1,3$, and 6 months), samples were resuspended in filtered water and analyzed for particle size, PDI, ZP, EE \%, and DL \%. The results were expressed as mean $\pm \operatorname{SEM}(n=6)$.

\section{Evaluation of the bioactivity of S-NLCs In vitro experiments}

\section{Cell culture}

Rat pheochromocytoma-derived PC12 cells were grown in Dulbecco's modified Eagle's medium supplemented with fetal bovine serum (10\%), horse serum
(5\%), streptomycin sulfate $(100 \mu \mathrm{g} / \mathrm{ml})$, penicillin $\mathrm{G}$ so$\operatorname{dium}(100 \mathrm{U} / \mathrm{ml})$, and amphotericin $\mathrm{B}(0.25 \mu \mathrm{g} / \mathrm{ml})$ in a humidified atmosphere with $5 \% \mathrm{CO}_{2}$ at $37{ }^{\circ} \mathrm{C}$. The culture media were changed every day and experiments were carried out $72 \mathrm{~h}$ after seeding the cells.

\section{In vitro model of ischemic stroke and treatments}

Oxygen-glucose deprivation (OGD) is a well-recognized in vitro model of stroke and may also be used to develop novel neuroprotective agents or investigate the mechanisms underlying the brain ischemia [36]. PC12 cells were exposed to OGD insult as previously described [37]. In brief, the original culture medium was replaced with pre-warmed glucose-free Hepes buffer in mM: Hepes (10), $\mathrm{NaCl}$ (150), $\mathrm{KCl}$ (5), $\mathrm{MgCl}_{2}$ (1), $\mathrm{CaCl}_{2}$ (2), $\mathrm{pH} 7.4\}$ and antimycotic-antibiotic solution. Then, the cells were transferred into the anaerobic chamber flushed with $95 \% \mathrm{~N}_{2}$ and $5 \% \mathrm{CO}_{2}$ for 1 and $8 \mathrm{~h}$ at $37{ }^{\circ} \mathrm{C}$. The deoxygenation of media was monitored using the oxygen-sensing probes (dOxyBead ${ }^{\mathrm{m}}$, Luxcel Biosciences, Cork, Ireland). In treatment groups, 20, 40, 80, and $100 \mu \mathrm{M}$ of sesamol [6-10], S-NLCs (containing 20, 40, 80 , and $100 \mu \mathrm{M}$ of sesamol), vehicle, or blank NLCs were added to the cell cultures $24 \mathrm{~h}$ before and upon the OGD onset. In the case of any effect, cells were treated with specific PI3K inhibitor, LY294002, dissolved in $0.2 \%$ dimethyl sulfoxide (DMSO) at concentrations of 10, 20, and $50 \mu \mathrm{M}[38,39] 20 \mathrm{~min}$ before the application of the effective agent.

\section{Cell viability assay}

The viability of PC12 cells was assessed using MTT (3[4,5-dimethylthiazol-2-yl]-2,5-diphenyl tetrazolium bromide) colorimetric assay [40]. $20 \mu \mathrm{l}$ of MTT stock solution ( $5 \mathrm{mg} / \mathrm{ml}$ in PBS) was added to each well $\left(1 \times 10^{4}\right.$ cells/ well) $4 \mathrm{~h}$ before the completion of re-oxygenation period. Then, the culture medium was aspirated and replaced with $100 \mu \mathrm{l}$ of DMSO and the plate was shaken for $10 \mathrm{~min}$ in order to dissolve the crystals and the absorbance was determined at $570 \mathrm{~nm}$ (Anthos 2020, Anthos Labtec Instruments, Austria). Cell viability was expressed as the percentage of untreated control cells (assuming the survival rate of $100 \%$ ) and presented as mean \pm SEM of six independent experiments $(n=6)$.

\section{Assessment of lactate dehydrogenase (LDH) activity}

LDH activity is correlated to the lysed cell numbers [41]. In order to quantify LDH activity, the media were removed following the re-oxygenation period and to obtain the maximum LDH release values, cells were washed twice with PBS and lysed with 1\% Triton X-100. The absorbance was recorded at $490 \mathrm{~nm}$ and the percentage of LDH release was calculated as follows; [LDH 
released into the media / (LDH released into the media $+\mathrm{LDH}$ released from the lysed cells) $] \times 100$.

\section{Morphological analysis}

Following the re-oxygentaion period, PC12 cells were cultured in 24-well plates and fixed using $4 \%$ paraformaldehyde for $30 \mathrm{~min}$ at room temperature. Then, the cells were thoroughly washed with $0.02 \mathrm{M} \mathrm{PBS}$ and stained with $10 \mathrm{mg} / \mathrm{ml}$ of Hoechst 33,258 in the dark. Images were captured using a fluorescence microscope (Leica, Germany). The condensed nuclei were counted in six visual fields $\left(\sim 0.3 \mathrm{~mm}^{2}\right)$ in each group and the percentage of condensed nuclei over the total number of cells was calculated as previously described [42].

\section{Assessment of the oxidative stress}

PC12 cells $\left(5 \times 10^{5}\right)$ were homogenized and centrifuged at $3500 \mathrm{~g}$ for $20 \mathrm{~min}$ at $4{ }^{\circ} \mathrm{C}$ and the supernatant was collected for analysis of the reduced glutathione (GSH) and malondialdehyde (MDA) contents and catalase (CAT) and superoxide dismutase (SOD) activities by appropriate kits. Protein content of the supernatant was determined by Bradford method [43]. MDA and GSH contents were determined at 530 and $412 \mathrm{~nm}$, respectively and expressed as $\mathrm{nM} / \mathrm{mg}$ protein [44, 45]. SOD and CAT activities were evaluated at 560 and $240 \mathrm{~nm}$, respectively and expressed as U/mg protein [46, 47].

\section{In vivo experiments}

\section{Animals}

Male Wistar rats (300-350 g) from our institution's laboratory animal centre were randomly assigned and housed under standard laboratory conditions with a 12$\mathrm{h}$ light/dark cycle and food pellets and water provided ad libitum. The protocol for in vivo experiments was approved by the Institutional Animal Care and Use Committee.

\section{Visualization of S-NLCs in rat brain}

S-NLCs were labeled with coumarin-6 [(3-(2' -benzothiazolyl)-7-diethylaminocoumarin] as previously described [48]. $1 \mathrm{~h}$ after the intravenous (i.v.) injection of $25 \mathrm{mg} /$ $\mathrm{kg}$ of the labelled S-NLCs, animals were deeply anaesthetized with intraperitoneal (i.p.) injection of ketamine/ xylazine, perfused with $0.9 \%$ saline and $4 \%$ paraformaldehyde, and the brains were stored at $-80{ }^{\circ} \mathrm{C}$ for 3 days. Afterwards, $20-\mu \mathrm{m}$ cryosections were provided using a cryostat (Leica, Germany) and were observed under the fluorescence microscope.

\section{Brain distribution study}

Animals were sacrificed at $0.25,0.5,0.75,1,2,4,6,8$, 10 , and $12 \mathrm{~h}$ following i.v. injection of $25 \mathrm{mg} / \mathrm{kg}$ of
S-NLCs or free sesamol and then the brain tissue samples were collected, washed, and weighed for further sesamol analysis [49].

\section{Animal groups, induction of ischemic stroke, and treatments}

Rats were randomly assigned into the following groups; intact $(n=6)$, sham $(n=10)$, ischemia/reperfusion $(\mathrm{I} / \mathrm{R})$, $\mathrm{I} / \mathrm{R}+$ vehicle, I/R + sesamol, I/R + S-NLCs, LY294002 + I/ $\mathrm{R}+$ sesamol or S-NLCs, and I/R + blank NLCs $(n=14 /$ group). Global cerebral ischemia was induced by a modified four-vessel occlusion (4-VO) method [50]. Animals exhibiting post-ischemic convulsions were excluded from the study. Sham-operated control group underwent the same surgical procedure without carotid ligation. Four days before and immediately after the stroke onset and during the reperfusion period, animals received once-daily i.v. injections of $5,10,20$, and $25 \mathrm{mg} / \mathrm{kg}$ of sesamol (dissolved in 0.5\% DMSO) [7-10], S-NLCs [containing the equivalent amounts of sesamol $(5,10$, 20, and $25 \mathrm{mg} / \mathrm{kg}$ )], vehicle, or blank NLCs. In the case of any effect, LY294002 was dissolved in 3\% DMSO and administered intracerebroventricularly (i.c.v.) at concentrations of 5,10 , and $25 \mu \mathrm{g} / \mu \mathrm{l}[51,52] 20 \mathrm{~min}$ prior to the application of the effective agent.

\section{Neurological deficit scoring}

Post-ischemic neurological deficits were scored on a 5point scale by an experimenter blinded to the treatment groups as follows, 0: no deficits, 1: difficulty in fully extending the contralateral forelimb, 2 : unable to extend the contralateral forelimb, 3 : mild circling to the contralateral side, 4: severe circling, and 5: falling to the contralateral side [53].

\section{Behavioural assessments}

Spatial learning and memory was assessed by Morris water-maze (MWM) test as previously described [54]. In order to assess the emotional memory, step-through passive avoidance test (STPAT) was performed [12].

\section{Assessment of the brain infarcted area}

Rats were anesthetized with $3.5 \%$ chloral hydrate and subjected to the intracardiac perfusion with $100 \mathrm{ml}$ of isotonic saline. Then, animals were killed by decapitation and the brains were removed and sliced coronally at 2$\mathrm{mm}$ intervals. Following the removal of dura mater and vascular tissue, slices were immersed into $2 \%$ 2,3,5-triphenyltetrazolium chloride (TTC, Sigma-Aldrich, Germany) solution in PBS ( $\mathrm{pH} 7.4$ ) for $30 \mathrm{~min}$ at $37^{\circ} \mathrm{C}$. Slices were turned over for several times and then washed twice in $10 \mathrm{ml}$ of saline and kept in $10 \%$ phosphate buffered formalin ( $\mathrm{pH}$ 7.4) overnight in a lightproof container for further photography. Infarcted areas 
of the brain sections were integrated and expressed as the percentage of total area [55].

\section{Histological assessments}

Neuronal loss in the hippocampal CA1 region was assessed as previously described [56]. Following the reperfusion period, animals were anesthetized with chloral hydrate $(400 \mathrm{mg} / \mathrm{kg}$, i.p.) and perfused intracardially with heparinized saline followed by $4 \%$ paraformaldehyde in 0.1 M PBS ( $\mathrm{pH} 7.4$ ). The brains were carefully removed, post-fixed in $4 \%$ paraformaldehyde for $24 \mathrm{~h}$ at $4{ }^{\circ} \mathrm{C}$, and embedded in paraffin. For histological assessments which were performed by two observers blind to the experimental set-up, $5 \mu \mathrm{m}$-thick coronal sections from the dorsal hippocampus were prepared by a rotary microtome and stained with cresyl violet. Images were captured using a microscope (Olympus Optical Co, LTD, Japan) equipped with a digital camera system (Pixera 600CL-CU, Pixera Corporation, Japan). The survived neurons in CA1 regions of hippocampi were counted in 6 frames $\left(1 \mathrm{~mm}^{2} /\right.$ each $)$ in five coronal sections and expressed as the percentage of total cell number.

\section{Biochemical analysis}

In other groups of animals, brains were removed and the hippocampi were immediately dissected on a frozen pad taken from a $-80{ }^{\circ} \mathrm{C}$ freezer [57], weighed, homogenized in ice-cold $0.1 \mathrm{M}$ phosphate buffer ( $\mathrm{pH} 7.4$ ), sonicated for $30 \mathrm{~s}$, and centrifuged at $12,000 \mathrm{~g}$ for $10 \mathrm{~min}$. Then, the supernatants were collected to assess MDA and GSH contents and SOD and CAT activities as aforementioned. The protein contents of the supernatants were determined by Bradford method [43].

\section{Statistical analysis}

The normal distribution of data was verified by ShapiroWilk test. Two- or three-way ANOVA followed by Tukey's post hoc test were applied to analyse the cytotoxicity, behavioural, and biochemical data. MannWhitney $U$ test was used to compare the neuron counts, brain infarcted area, and neurological deficit scores. Student's t-test was used in brain distribution study. Data are presented as mean \pm SEM and the statistical significance was set at $P<0.05$.

\section{Results}

\section{Characterization of S-NLCs}

S-NLCs dispersions were successfully prepared by a modified high-pressure homogenization technique without signs of phase separation or colour change during at least 1-month visual inspection. Using different ratios of solid and liquid lipids, sesamol and lipid, and surfactants or sonication time, various S-NLCs formulations with different physicochemical properties were prepared.
Application of the higher amount of oil lipid or surfactant resulted in the smaller particle size and higher entrapment efficiency (Table 1). Considering the EE\%, DL\%, and particle size, S-NLCs7 (Table 1) was selected as the optimal formulation for further experimental procedures. Based on the representative SEM images, the freshly-prepared S-NLCs (Fig. 1a) or those three months after freeze-drying (Fig. 1b) were spherical in shape and uniform in size. In DSC thermograms, pure sesamol showed a sharp endothermic peak around $64.59{ }^{\circ} \mathrm{C}$ (Fig. 2b) and the melting peak of cetyl palmitate was observed at $54.86{ }^{\circ} \mathrm{C}$ (Fig. 2c). The blank NLCs showed melting peak at $47.63{ }^{\circ} \mathrm{C}$ (Fig. $2 \mathrm{~d}$ ), while, S-NLCs displayed a melting peak at $43.81{ }^{\circ} \mathrm{C}$ three months after freeze drying (Fig. 2a). The release of sesamol from the solution was faster than S-NLCs formulation in which a controlled release pattern was observed (Fig. 3). In various S-NLCs formulations, the total release of $52.7 \pm 4.8$ to $77.8 \pm 6.2 \%$ was achieved at the end of $48 \mathrm{~h}$ (Table 1 ). As shown in Table 2, the lyophilized nanoparticles remained stable at $4{ }^{\circ} \mathrm{C}$ without significant alterations in the particle size, PDI, ZP, EE or DL \% during 6 months of storage $(P>0.05)$.

\section{Evaluation of the bioactivity of S-NLCs MTT assay}

Following 1- and 8-h OGD insult, cell viability was significantly decreased (Fig. $4, P<0.001$ vs. control). Sesamol $(80$ and $100 \mu \mathrm{M})$ prevented the cell loss after 1 -h OGD/R (Fig. $4 \mathrm{a}, \mathrm{P}<0.05, P<0.01$ vs. OGD or OGD + vehicle group), while, it was ineffective after 8 -h OGD/R (Fig. 4b, $P>0.05$ ). S-NLCs (containing 80 and $100 \mu \mathrm{M}$ of sesamol) significantly prevented the cell loss after 1 - and 8-h OGD/R (Fig. 4a and b, $P<0.05, P<0.001$ ). Pretreatment with LY294002 $(50 \mu \mathrm{M})$ prevented the cytoprotective effects of sesamol or S-NLCs (Figs $4 \mathrm{a}$ and b, $P>0.05$ vs. OGD or OGD + vehicle group). Pre-treatment with lower doses of LY294002 showed no effect and this antagonist had no effect by itself (data not shown). Sesamol or S-NLCs $(20,40,80$, and $100 \mu \mathrm{M})$ did not induce cytotoxicity in PC12 cells under the normal condition (not shown).

\section{$L D H$ release}

LDH release was significantly increased in PC12 cells exposed to 1 - or 8 -h OGD/R (Fig. 5, $P<0.001$ vs. control). Sesamol or S-NLCs $(80$ and $100 \mu \mathrm{M})$ prevented the enhancement of $\mathrm{LDH}$ activity due to 1 -h OGD/R (Fig. 5a, $\mathrm{P}<0.01$ and $\mathrm{P}<0.001$ vs. OGD or OGD + vehicle group). S-NLCs, but not sesamol, reduced LDH release following 8-h OGD/R (Fig. 5b, $P<0.05$ vs. OGD or OGD + vehicle group). Pretreatment with LY294002 $(50 \mu \mathrm{M})$ reversed the effects of sesamol or S-NLCs (Fig. $5 \mathrm{a}$ and b, P>0.05 vs. OGD 
Table 1 Physichochemical properties of sesamol-loaded NLCS

\begin{tabular}{|c|c|c|c|c|c|c|}
\hline Formulation code & Particle size (nm) & PDI & $\mathrm{ZP}(\mathrm{mV})$ & EE (\%) & $\mathrm{DL}(\%)$ & $\begin{array}{l}\text { DR } \\
\text { after } 48 \text { h (\%) }\end{array}$ \\
\hline $\begin{array}{l}\text { S-NLC1 } \\
\text { S-NLC2 } \\
\text { S-NLC3 } \\
\text { S-NLC4 } \\
\text { S-NLC5 } \\
\text { S-NLC6 } \\
\text { S-NLC7 } \\
\text { S-NLC8 } \\
\text { Blank NLCs }\end{array}$ & $\begin{array}{l}137.4 \pm 9.2 \\
123.6 \pm 7.4 \\
104.3 \pm 8.7 \\
66.3 \pm 1.6 \\
73.8 \pm 4.3 \\
81.6 \pm 3.7 \\
92.3 \pm 6.2 \\
124.7 \pm 9.4 \\
52.4 \pm 6.7\end{array}$ & $\begin{array}{l}0.37 \pm 0.04 \\
0.32 \pm 0.01 \\
0.28 \pm 0.03 \\
0.12 \pm 0.07 \\
0.18 \pm 0.07 \\
0.21 \pm 0.05 \\
0.23 \pm 0.04 \\
0.29 \pm 0.09 \\
0.13 \pm 0.06\end{array}$ & $\begin{array}{l}-21.8 \pm 0.51 \\
-26.2 \pm 0.37 \\
-23.3 \pm 0.63 \\
-25.8 \pm 0.58 \\
-21.4 \pm 0.47 \\
-19.5 \pm 0.53 \\
-27.9 \pm 0.56 \\
-25.4 \pm 0.45 \\
-18.7 \pm 0.72\end{array}$ & $\begin{array}{l}41.4 \pm 2.6 \\
47.7 \pm 3.2 \\
66.3 \pm 8.5 \\
94.3 \pm 3.7 \\
92.7 \pm 4.3 \\
89.2 \pm 6.4 \\
94.2 \pm 1.8 \\
91.4 \pm 2.5\end{array}$ & $\begin{array}{l}1.45 \pm 0.14 \\
1.63 \pm 0.08 \\
1.78 \pm 0.12 \\
3.11 \pm 0.06 \\
6.13 \pm 0.17 \\
11.32 \pm 3.4 \\
28.51 \pm 1.2 \\
49.92 \pm 3.7\end{array}$ & $\begin{array}{l}52.7 \pm 4.8 \\
57.3 \pm 5.3 \\
68.5 \pm 4.7 \\
82.3 \pm 5.7 \\
77.8 \pm 6.2 \\
74.6 \pm 3.9 \\
69.8 \pm 5.4 \\
60.3 \pm 1.8\end{array}$ \\
\hline & & & $-18.7 \pm 0.72$ & - & - & - \\
\hline
\end{tabular}

Data are represented as mean $\pm \operatorname{SEM}(n=6)$

( $P D I$ polydispersity index, ZP zeta potential, EE entrapment efficiency, DL drug loading, DR drug release, S-NLCS sesamol-loaded nanostructured lipid carriers)

or OGD + vehicle group), while, the lower doses of LY294002 showed no effect (data not shown). LY294002 showed no effect per se (not shown). Sesamol or S-NLCs $(20,40,80$, and $100 \mu \mathrm{M})$ did not significantly affect LDH release form $\mathrm{PC} 12$ cells under the normal condition (not shown).
Morphological alterations in PC12 cells induced by OGD

Exposure to 1- or 8-h OGD/R resulted in the reduced cell number and alteration in cellular morphology (Fig. 6b and c, respectively) as compared to the control (Fig. 6a). Sesamol $(100 \mu \mathrm{M})$ attenuated the cellular damage due to 1-h OGD (Fig. 6d), however, it was ineffective
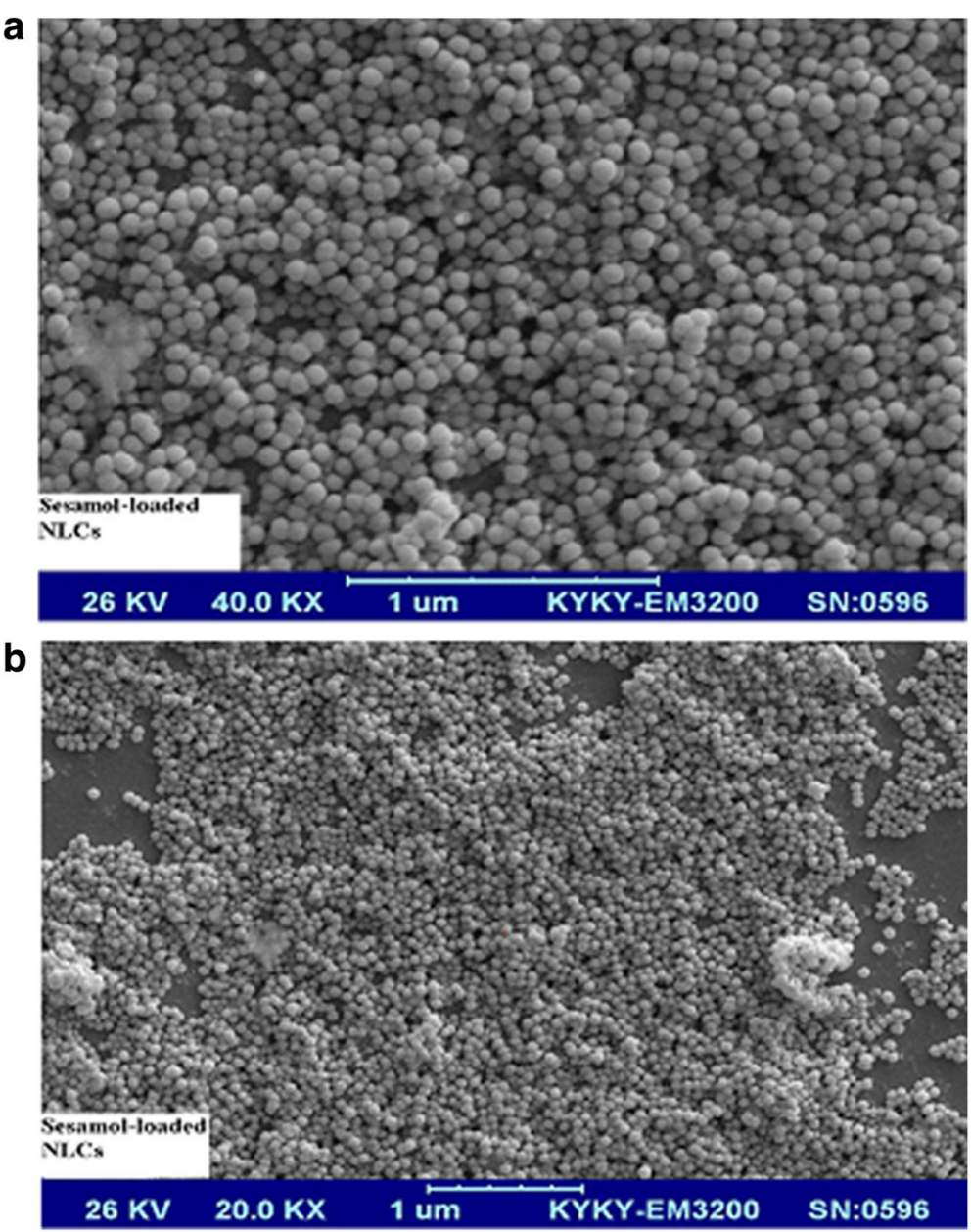

Fig. 1 Scanning electron micrographs of sesamol-loaded NLCs. The spherical shape and smooth surface with relatively uniform size are observed in highly-concentrated nanoparticles (formulation S-NLC7). a fresh sample with higher magnification, no pore on the nanoparticle surface is observed, b The non-aggregated and finely-dispersed nanoparticles three months after freeze drying 


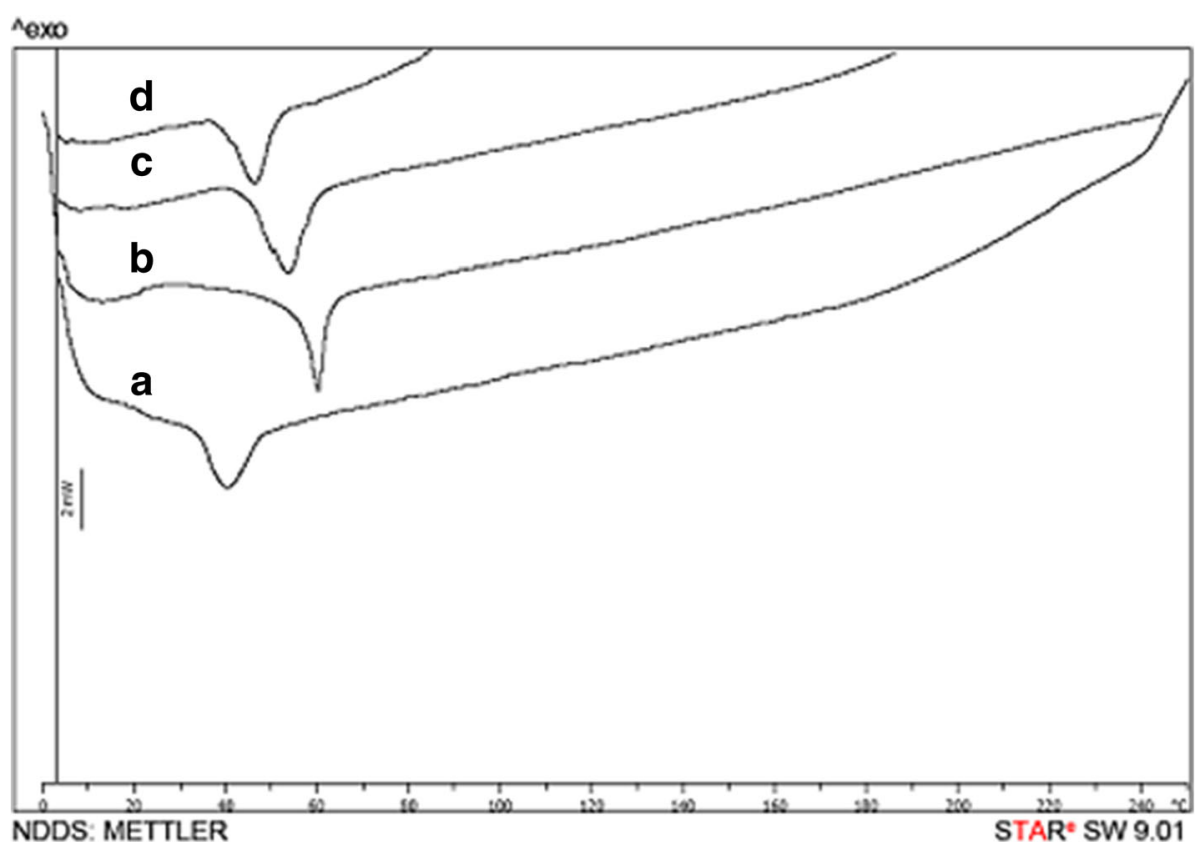

Fig. 2 The overlaid DSC thermograms. a: sesamol-loaded NLCs three months after freeze drying (formulation S-NLC7), b: sesamol, c: cetyl palmitate, d: blank NLCs. (DSC: differential scanning calorimetry)

following 8-h OGD insult (Fig. 6f). Cells treated with S-NLCs (containing $100 \mu \mathrm{M}$ of sesamol) displayed improved morphology following both 1- and 8-h OGD (Fig. 6e and g, respectively). Pretreatment with LY294002 $(50 \mu \mathrm{M})$ prevented the cytoprotective effect of S-NLCs (Fig. 6h). The significant enhancement of condensed nuclei induced by 1 - or 8 -h OGD (Fig. 6i and j, $P<0.001$ vs. the control) was prevented by 80 and $100 \mu \mathrm{M}$ of sesamol or S-NLCs after 1-h OGD (Fig. 6 i, $P<0.01, P<0.001$ ). $S-N L C s$ (containing 80

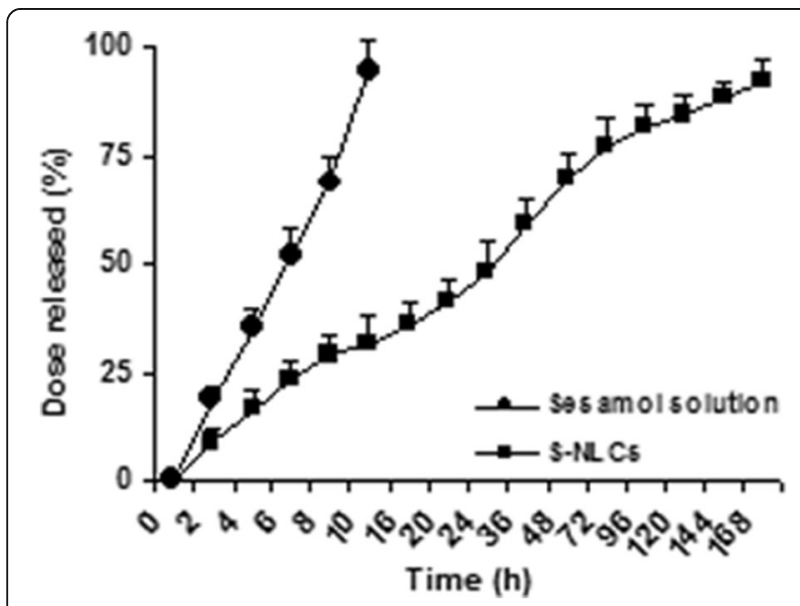

Fig. 3 In vitro release profile of sesamol. A controlled release pattern of sesamol from S-NLCs is observed. Data are expressed as the mean \pm SEM $(n=3)$. (S-NLCs: sesamol-loaded nanostructured lipid carriers) and $100 \mu \mathrm{M}$ of sesamol), but not free sesamol, prevented the formation of condensed nuclei due to 8 -h OGD insult (Fig. 6j, $P<0.001$ ). Pretreatment with LY294002 $(50 \mu \mathrm{M})$ prevented the cytoprotective effects (Fig. 6i and j, $P>0.05$ vs. OGD or OGD + vehicle group), however, the lower doses of this antagonist were ineffective (not shown). LY294002 showed no effect by itself (not shown).

\section{The effects of sesamol or S-NLCS on OGD-induced oxidative stress}

As shown in Table 3, induction of OGD for 1 or 8 h resulted in a significant elevation of MDA level and reduction of GSH content and CAT and SOD activities in PC12 cells $(P<0.001$ vs. control). Following 1 -h OGD, 80 and $100 \mu \mathrm{M}$ of free sesamol reduced MDA $(P<0.05$ and $P<0.01$ vs. OGD and OGD + vehicle groups), and elevated GSH content $(P<0.05)$ and activities of SOD $(P<0.05, P<0.01)$ and CAT $(P<0.001)$, however, sesamol was ineffective following 8 -h OGD $(P>0.05)$. SNLCs (containing 80 and $100 \mu \mathrm{M}$ of sesamol) showed antioxidant effects after both 1- and 8-h OGD (MDA: $P<0.01, P<0.001$; GSH: $P<0.05$; SOD: $P<0.05, P<$ 0.001; and CAT: $\mathrm{P}<0.001$ vs. OGD or OGD + vehicle group). Pre-treatment with LY294002 (50 $\mu \mathrm{M})$ prevented the antioxidant effects $(P>0.05$ vs. OGD or OGD + vehicle group), while the lower doses were ineffective (not shown). LY294002 showed no effect by itself (not shown). 
Table 2 The stability profile of sesamol-loaded NLCS

\begin{tabular}{|c|c|c|c|c|c|c|c|c|c|}
\hline Initial & & & & & 1st Month & & & & \\
\hline Size & PDI & ZP & $\mathrm{EE} \%$ & DL\% & Size & PDI & ZP & $\mathrm{EE} \%$ & DL\% \\
\hline $92.3 \pm 6.2 \pm 1.2$ & $0.23 \pm 0.04$ & $-27.9 \pm 0.5$ & $94.2 \pm 1.8$ & 28.51 & $95.1 \pm 4.9$ & $0.19 \pm 0.09$ & $-25.3 \pm 0.3$ & $92.7 \pm 5.4$ & $26.84 \pm 1.7$ \\
\hline 3rd Month & & & & & 6th Month & & & & \\
\hline Size & PDI & ZP & $\mathrm{EE} \%$ & DL\% & Size & PDI & ZP & $\mathrm{EE} \%$ & DL\% \\
\hline $94.3 \pm 4.1$ & $0.21 \pm 0.07$ & $-26.5 \pm 0.4$ & $95.5 \pm 2.4$ & $28.03 \pm 1.9$ & $99.8 \pm 3.3$ & $0.19 \pm 0.07$ & $-23.7 \pm 0.8$ & $89.62 \pm 4.7$ & $25.86 \pm 0.9$ \\
\hline
\end{tabular}

Data are represented as mean $\pm \operatorname{SEM}(n=6)$

( $P D I$ polydispersity index, ZP zeta potential, EE entrapment efficiency, DL drug loading, S-NLCs sesamol-loaded nanostructured lipid carriers)

\section{In vivo experiments}

\section{Brain delivery of S-NLCs}

Using coumarin-6-loaded nanoparticles, S-NLCs entry into the hippocampus was demonstrated (Fig. 7a). Based on the brain distribution study, administration of S-NLCs provided a significantly higher brain concentrations of sesamol as compared to the free sesamol (Fig. $7 \mathrm{~b}, P<0.001$ ).

\section{The effects of sesamol solution or S-NLCS on I/R-induced neurobehavioral deficits}

As shown Table 4, neurological deficit score was significantly increased in $\mathrm{I} / \mathrm{R}$ or $\mathrm{I} / \mathrm{R}+$ vehicle group $(P<0.001$ vs. sham or intact group) and decreased in the groups treated with S-NLCs containing 20 or $25 \mathrm{mg} / \mathrm{kg}$ of sesamol ( $P<0.01$ and $P<0.001$ vs. $\mathrm{I} / \mathrm{R}$ or $\mathrm{I} / \mathrm{R}+$ vehicle group $)$. Furthermore, global ischemia impaired the learning and

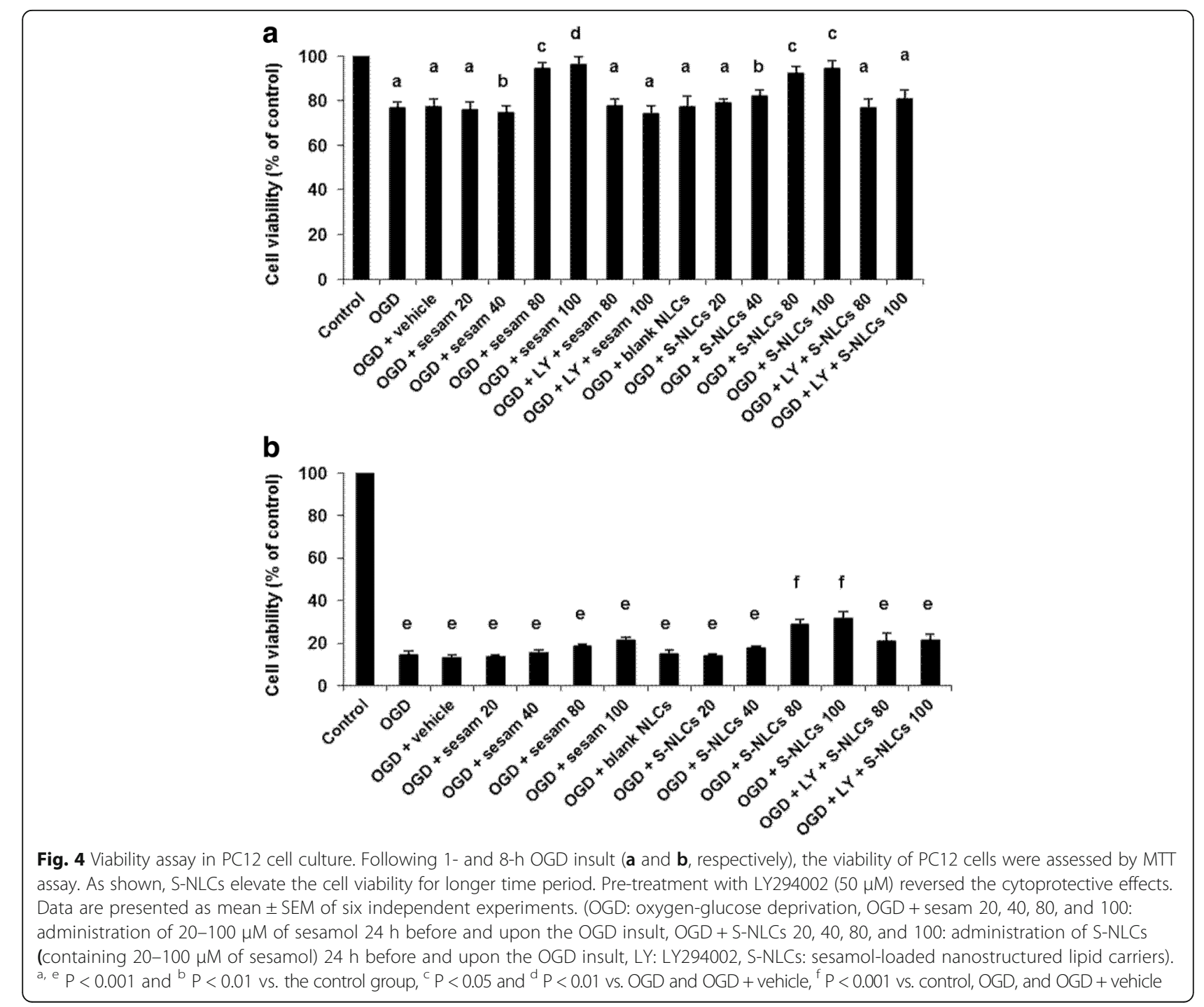




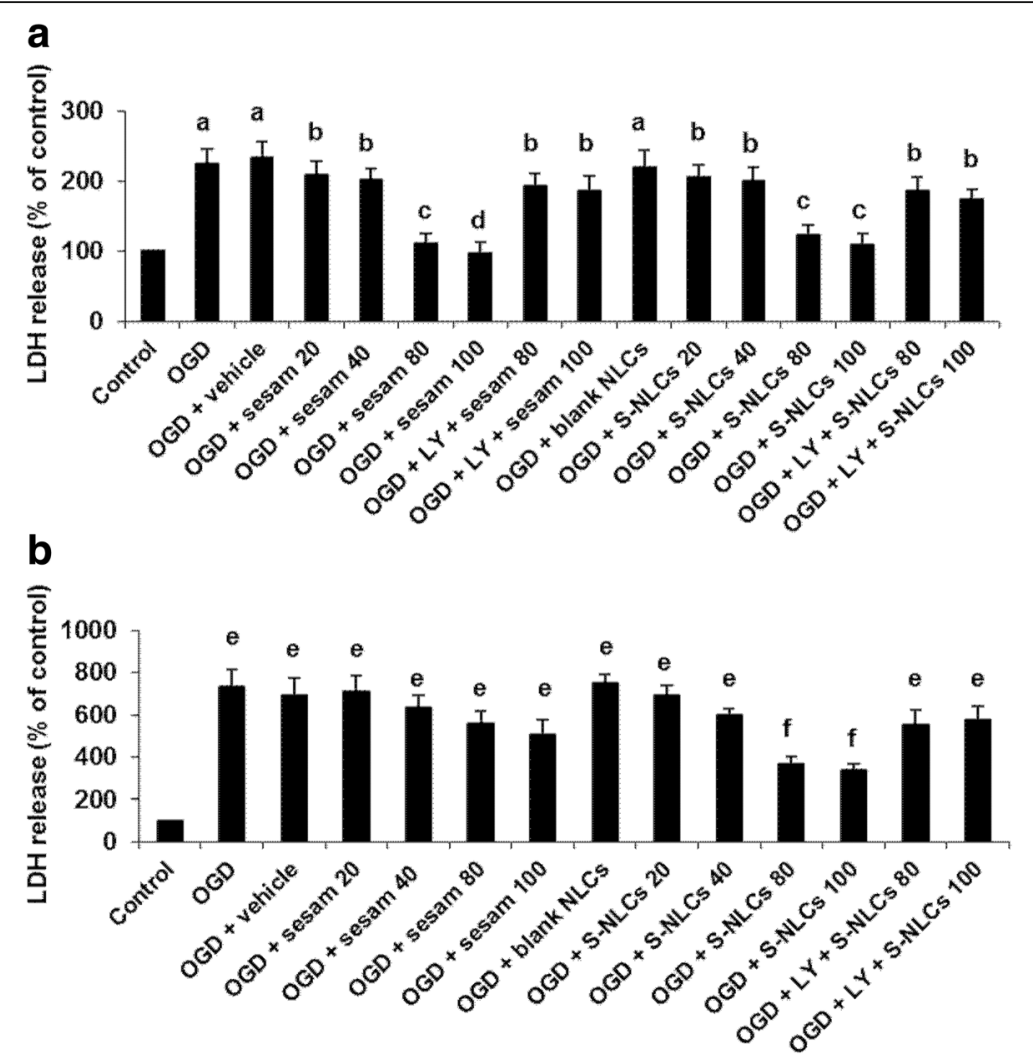

Fig. 5 The effect of OGD, sesamol, or S-NLCS on LDH release. S-NLCS effectively prevented the enhancement of LDH release after both 1-h (a) and 8-h OGD (b) that was reversed due to the pre-treatment with LY294002 $(50 \mu \mathrm{M})$. Data are presented as the mean \pm SEM of six independent experiments. ${ }^{a}, \mathrm{e} P<0.001$, and ${ }^{\mathrm{b}} \mathrm{P}<0.01$ vs. the control, ${ }^{c, d} \mathrm{~d}<0.01$ vs. $\mathrm{OGD}$ and $\mathrm{OGD}+$ vehicle, $^{f} \mathrm{P}<0.05$ vs. control and $\mathrm{P}<0.001$ vs. $O G D$ and OGD + vehicle. (LDH: lactate dehydrogenase, OGD: oxygen-glucose deprivation, LY: LY294002, S-NLCs: sesamol-loaded nanostructured lipid carriers)

memory as revealed by MWMT or STPAT $(P<0.001$ vs. sham or intact group). Treatment with S-NLCs (20 and $25 \mathrm{mg} / \mathrm{kg}$ ) significantly improved the learning and memory $(P<0.05$ and $P<0.001$ vs. $\mathrm{I} / \mathrm{R}$ or $\mathrm{I} / \mathrm{R}+$ vehicle group $)$. The free sesamol failed to affect I/R-induced neurobehavioral deficits at any dose tested $(P>0.05$ vs. $\mathrm{I} / \mathrm{R}$ or $\mathrm{I} / \mathrm{R}+$ vehicle group). Pretreatment with LY294002 $(25 \mu \mathrm{g} / \mu \mathrm{l})$ abolished the ameliorative effects of S-NLCs $(P>0.05$ vs. $\mathrm{I} / \mathrm{R}$ or I/R + vehicle group). Pretreatment with lower doses of LY294002 showed no effect (not shown). LY294002 had no effect by itself (not shown).

\section{The effects of S-NLCs or sesamol on the brain infarction induced by global cerebral $I / R$}

TTC staining revealed the significantly increased infarcted areas in $I / R$ group [Fig. $8 b$ and $f, P<0.001$ vs. sham group (Fig. 8a and f)]. FA even at the highest dose tested $(25 \mathrm{mg} / \mathrm{kg})$ failed to prevent I/R-induced brain infarction (Fig. $8 \mathrm{~d}$ and $\mathrm{f}, \mathrm{P}>0.05$ vs. I/R group), while, FANLCs $(25 \mathrm{mg} / \mathrm{kg}$ ) showed protective effect (Fig. 8c and f, $P<0.01$ vs. I/R group). Pre-treatment with LY294002 (25 $\mu \mathrm{g} / \mu \mathrm{l}$ ) abolished the protective effect of FA-NLCs (Fig. 8e and f, $P>0.05$ vs. I/R group). The lower doses of LY294002 were ineffective and the antagonist showed no effect by itself (not shown).

\section{The effects of sesamol or S-NLCS on I/R-induced neuronal damage in the hippocampal CA1 region}

Based on the histological evaluation, global cerebral ischemia induced the neuronal damage in the hippocampal CA1 region as revealed by the formation of darkstained cells with dysmorphic shape (Fig. 9b) and less survived neurons (Fig. 9f, $P<0.001$ vs. sham or intact group) as compared to the sham group with closely arranged round cells including the distinct nucleus and nucleolus (Fig. 9a). Treatment with S-NLCs $(25 \mathrm{mg} / \mathrm{kg})$ improved the cell morphology (Fig. 9c) and significantly increased the number of survived cells (Fig. 9f, $P<0.001$ vs. I/R or $I / R+$ vehicle group), while, free sesamol even at the highest dose tested $(25 \mathrm{mg} / \mathrm{kg})$ was ineffective against I/R-induced neuronal damage (Figs 9d and f, $P>0.05)$. Pre-treatment with LY294002 $(25 \mu \mathrm{g} / \mu \mathrm{l})$ abolished the neuroprotective effect of S-NLCs (Figs. 9e and f, $P>0.05$ vs. I/R group or $I / R+$ vehicle group), while, pretreatment with lower doses of LY294002 showed no 

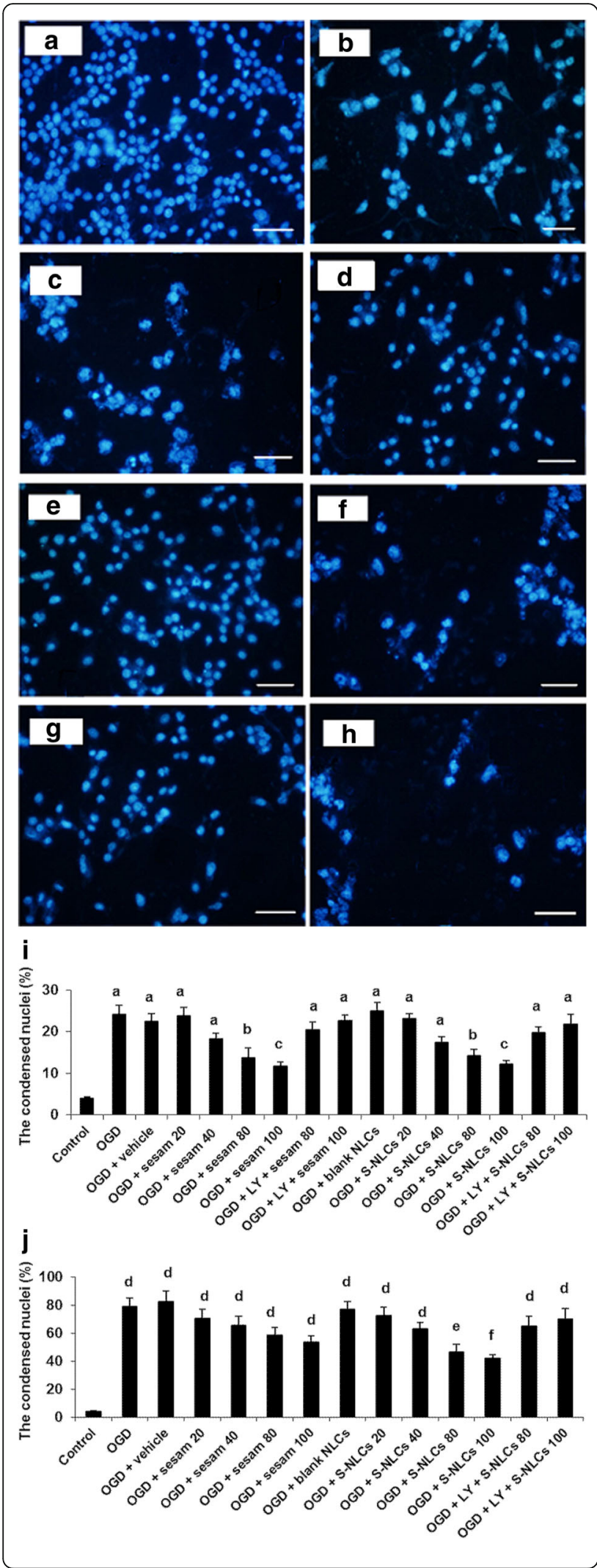

Fig. 6 Morphological alterations in PC12 cells exposed to OGD and quantitative analysis of the condensed nuclei. A high density of round cells is demonstrated in the control cells, while, alteration in the cellular morphology and enhancement of condensed nuclei occurred following 1- and 8-h OGD. Treatment of PC12 cells with sesamol or S-NLCs $24 \mathrm{~h}$ before and upon the exposure to 1-h OGD resulted in the ameliorative effects. Unlike free sesamol, S-NLCs preserved the protective effects following the longer exposure to OGD insult. Pre-treatment with LY294002 $(50 \mu \mathrm{M})$ reversed the cytoprotective effects. a: control cells, b: 1-h OGD insult, c: 8-h OGD insult, c: sesamol $(100 \mu M)+1$-h OGD, e: S-NLCs $(100 \mu M)+1$-h OGD, f: sesamol $(100 \mu \mathrm{M})+8-h$ OGD, g: S-NLCS $(100 \mu \mathrm{M})+8-\mathrm{h}$ OGD, h: LY294002 $(50 \mu \mathrm{M})+$ S-NLCs $(100 \mu \mathrm{M})+8-\mathrm{h}$ OGD (scale bars: $50 \mu \mathrm{m})$, i: $(1-\mathrm{h}$ OGD insult), $\mathbf{j}$ (8-h OGD insult). The numbers of condensed nuclei have been represented as the percentage of total number of nuclei counted. Data are mean \pm SEM of six different cell culture preparations. ${ }^{a, d} p<0.001$ vs. the control group, ${ }^{b} \mathrm{P}<0.01$ vs. control, OGD, and OGD + vehicle, $P<0.05$ vs. control, and $P<0.001$ vs. OGD and OGD + vehicle, ${ }^{e}$

$\mathrm{P}<0.001$ vs. control and $\mathrm{P}<0.01$ vs. $\mathrm{OGD}$ and $\mathrm{OGD}+$ vehicle, $^{\mathrm{f}} \mathrm{P}<0.001$ vs. control, OGD, and OGD + vehicle. (OGD: oxygen-glucose deprivation, LY: LY294002, S-NLCs: sesamol-loaded nanostructured lipid carriers)

effect (not shown). This PI3K antagonist showed no effect by itself (not shown).

\section{The effects of sesamol or S-NLCS on I/R-induced oxidative stress in the hippocampus}

As shown in Table 5, I/R led to the significant elevation of MDA $(P<0.01)$ and reduction of GSH $(P<0.001)$, SOD $(P<0.001)$, and CAT $(P<0.001)$ as compared to the sham or intact group. This, was prevented by 20 and $25 \mathrm{mg} / \mathrm{kg}$ of S-NLCs (MDA: $P<0.01$; GSH: $P<0.05, P<$ 0.01; SOD: $P<0.01, P<0.001$; and CAT: $P<0.01$ vs. I/R or $\mathrm{I} / \mathrm{R}+$ vehicle.), while, free sesamol failed to prevent $\mathrm{I} /$ R-induced oxidative stress at any dose tested $(P>0.05$ vs. I/R or $I / R+$ vehicle). Pre-treatment with LY294002 $(25 \mu \mathrm{g} / \mu \mathrm{l})$ reversed the protective effect of S-NLCs against $\mathrm{I} / \mathrm{R}$-induced oxidative stress $(P>0.05$ vs. I/R group or $\mathrm{I} / \mathrm{R}+$ vehicle group), however, the lower doses of LY294002 were ineffective (not shown). LY294002 showed no effect by itself (not shown).

\section{Discussion}

Cerebral stroke has remained a major healthcare challenge. Recombinant tissue plasminogen activator ( $r$-tPA) remains the sole medication, however, it should be administered in a short time after onset of symptoms [1]. Over the last decade, phenolic compounds such as sesamol have been the focus of intense research due to their antioxidant and neuroprotective properties, however, poor solubility or rapid metabolism may negatively affect their effectiveness [12, 13, 58-61]. In the present study, we have prepared S-NLCs as the nanoreserviors to provide longer-lasting therapeutic effects for sesamol in both in vitro and in vivo models of ischemic stroke. SNLCs showed high stability profile during 6-month 
Table 3 Effects of sesamol or S-NLCs on the biochemical parameters following the ischemic insult

\begin{tabular}{|c|c|c|c|c|c|c|c|c|}
\hline \multirow[t]{2}{*}{ Groups } & \multicolumn{2}{|c|}{ MDA (nM/mg protein) } & \multicolumn{2}{|c|}{ GSH (nM/mg protein) } & \multicolumn{2}{|c|}{$\mathrm{SOD}(\mathrm{U} / \mathrm{mg}$ protein) } & \multicolumn{2}{|c|}{ CAT (U/mg protein) } \\
\hline & $1 \mathrm{~h}$ & $8 \mathrm{~h}$ & $1 \mathrm{~h}$ & $8 \mathrm{~h}$ & $1 \mathrm{~h}$ & $8 \mathrm{~h}$ & $1 \mathrm{~h}$ & $8 \mathrm{~h}$ \\
\hline $\begin{array}{l}\text { Control } \\
\text { OGD } \\
\text { OGD + vehicle } \\
\text { OGD + sesamol }(20 \mu \mathrm{M}) \\
\text { OGD + sesamol }(40 \mu \mathrm{M}) \\
\text { OGD + sesamol }(80 \mu \mathrm{M}) \\
\text { OGD + sesamol }(100 \mu \mathrm{M}) \\
\text { LY + OGD + sesamol }(80 \mu \mathrm{M}) \\
\text { LY + OGD + sesamol }(100 \mu \mathrm{M}) \\
\text { OGD + blank NLCs } \\
\text { OGD + S-NLCs }(20 \mu \mathrm{M}) \\
\text { OGD + S-NLCs }(40 \mu \mathrm{M}) \\
\text { OGD + S-NLCs }(80 \mu \mathrm{M}) \\
\text { OGD + S-NLCs }(100 \mu \mathrm{M}) \\
\text { LY + OGD + S-NLCS }(80 \mu \mathrm{M}) \\
\text { LY + OGD + S-NLCs }(100 \mu \mathrm{M})\end{array}$ & $\begin{array}{l}0.53 \pm 0.04 \\
1.32 \pm 0.10^{* *} \\
1.37 \pm 0.14^{* *} \\
1.38 \pm 0.23^{* *} \\
1.22 \pm 0.19^{* *} \\
0.65 \pm 0.06^{\&} \\
0.59 \pm 0.03^{\pi} \\
1.43 \pm 0.09^{* *} \\
1.28 \pm 0.15^{* *} \\
1.35 \pm 0.16^{* *} \\
1.15 \pm 0.11^{*} \\
1.17 \pm 0.08^{*} \\
0.58 \pm 0.03^{*} \\
0.47 \pm 0.04^{\Sigma} \\
1.23 \pm 0.07^{*} \\
1.37 \pm 0.19^{* *}\end{array}$ & $\begin{array}{l}0.57 \pm 0.05 \\
2.02 \pm 0.25^{* * *} \\
1.91 \pm 0.14^{* * *} \\
2.12 \pm 0.21^{* * *} \\
1.76 \pm 0.13^{* * *} \\
1.88 \pm 0.11^{* * *} \\
1.79 \pm 0.09^{* * *} \\
1.94 \pm 0.22^{* *} \\
1.67 \pm 0.19^{* *} \\
2.07 \pm 0.17^{* * *} \\
1.98 \pm 0.10^{* * *} \\
1.92 \pm 0.16^{* * *} \\
1.02 \pm 0.16^{\ominus} \\
0.92 \pm 0.07^{\infty} \\
1.48 \pm 0.33^{* *} \\
1.27 \pm 0.08^{* * *}\end{array}$ & $\begin{array}{l}12.97 \pm 1.19 \\
7.13 \pm 0.49^{* * *} \\
7.29 \pm 0.57^{* * *} \\
7.92 \pm 0.48^{* * *} \\
7.22 \pm 0.45^{* * *} \\
10.62 \pm 0.83^{\#} \\
10.29 \pm 0.52^{\Delta} \\
7.56 \pm 0.62^{* *} \\
8.19 \pm 0.62^{* *} \\
7.58 \pm 0.67^{* * *} \\
7.38 \pm 0.81^{* * *} \\
8.25 \pm 0.89^{* *} \\
10.87 \pm 0.55^{\lessgtr} \\
11.03 \pm 0.42 \odot \\
8.07 \pm 0.24^{* * *} \\
7.58 \pm 0.13^{* * *}\end{array}$ & $\begin{array}{l}12.71 \pm 0.93 \\
3.81 \pm 0.36^{* * * *} \\
3.65 \pm 0.22^{* * * *} \\
3.58 \pm 0.17^{* * *} \\
3.81 \pm 0.25^{* * *} \\
4.83 \pm 0.28^{* * *} \\
4.17 \pm 0.13^{* * *} \\
4.33 \pm 0.24^{* * *} \\
4.61 \pm 0.17^{* * *} \\
3.47 \pm 0.18^{* * *} \\
4.26 \pm 0.39^{* * * *} \\
4.75 \pm 0.17^{* * *} \\
6.67 \pm 0.59^{@} \\
7.49 \pm 0.38^{ \pm} \\
4.25 \pm 0.19^{* * *} \\
4.72 \pm 0.22^{* * *}\end{array}$ & $\begin{array}{l}39.67 \pm 2.94 \\
24.94 \pm 2.38^{* * *} \\
23.63 \pm 1.82^{* * *} \\
23.02 \pm 2.11^{* * *} \\
26.83 \pm 1.96^{* *} \\
37.06 \pm 1.89^{\omega} \\
36.94 \pm 2.14^{\Omega} \\
25.17 \pm 1.03^{* * *} \\
23.86 \pm 2.87^{* *} \\
25.17 \pm 2.34^{* * *} \\
27.70 \pm 1.94^{* *} \\
29.38 \pm 1.33^{*} \\
35.33 \pm 2.12^{€} \\
34.52 \pm 1.84 \\
24.13 \pm 1.08^{* *} \\
22.96 \pm 1.85^{* * *}\end{array}$ & $\begin{array}{l}38.29 \pm 1.87 \\
18.77 \pm 1.14^{* * *} \\
19.35 \pm 1.29^{* * *} \\
19.83 \pm 1.82^{* * *} \\
18.22 \pm 2.16^{* * *} \\
21.63 \pm 1.96^{* * *} \\
20.17 \pm 1.07^{* * *} \\
18.73 \pm 2.45^{* * *} \\
21.08 \pm 1.66^{* * *} \\
18.16 \pm 1.01^{* * *} \\
17.38 \pm 1.64^{* * *} \\
20.52 \pm 2.02^{* * *} \\
27.84 \pm 2.14^{ø} \\
29.03 \pm 1.23^{*} \\
17.88 \pm 1.13^{* * *} \\
21.32 \pm 1.89^{* * *}\end{array}$ & $\begin{array}{l}6.83 \pm 0.44 \\
2.44 \pm 0.19^{* * *} \\
2.32 \pm 0.25^{* * *} \\
2.45 \pm 0.14^{* * *} \\
2.76 \pm 0.27^{* * *} \\
4.28 \pm 0.36^{\oplus} \\
4.86 \pm 0.19^{Q} \\
2.34 \pm 0.23^{* *} \\
2.69 \pm 0.14^{* * *} \\
2.36 \pm 0.15^{* * *} \\
2.23 \pm 0.15^{* * *} \\
3.42 \pm 0.24^{* * *} \\
4.86 \pm 0.27^{\beta} \\
4.73 \pm 0.14^{\boldsymbol{p}} \\
3.11 \pm 0.19^{* * *} \\
2.65 \pm 0.27^{* *}\end{array}$ & $\begin{array}{l}6.88 \pm 0.47 \\
1.49 \pm 0.18^{* * *} \\
1.53 \pm 0.16^{* * *} \\
1.47 \pm 0.13^{* * *} \\
1.64 \pm 0.11^{* * *} \\
1.59 \pm 0.16^{* * *} \\
1.73 \pm 0.08^{* * *} \\
1.29 \pm 0.18^{* *} \\
1.55 \pm 0.07^{* * *} \\
1.54 \pm 0.12^{* * *} \\
1.71 \pm 0.18^{* * *} \\
1.85 \pm 0.21^{* * *} \\
2.83 \pm 0.26^{\dagger} \\
2.96 \pm 0.23^{*} \\
1.63 \pm 0.09^{* * *} \\
1.96 \pm 0.16^{* * *}\end{array}$ \\
\hline
\end{tabular}

PC12 cells have been exposed to 1 and $8 \mathrm{~h}$ oxygen-glucose deprivation. Each value represents the mean \pm SEM of six independent experiments (MDA malondialdehyde, GSH reduced glutathione, CAT catalase, SOD superoxide dismutase, OGD oxygen-glucose deprivation, S-NLCS sesamol-loaded nanostructured lipid carriers, $L Y$ LY294002)

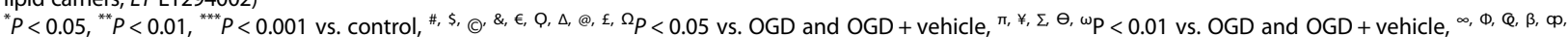
${ }^{*} P<0.001$ vs. control, $O G D$, and $O G D+$ vehicle, ${ }^{\circ} P<0.01$ vs. control and $P<0.05$ vs. $O G D$ and $O G D+$ vehicle, ${ }^{4,}, \mathrm{P}<0.001$ vs. control and $P<0.01$ vs. $O G D$ and OGD + vehicle

follow up (Table 2) that might be due to the binary mixture of solid and liquid lipids which elevates the imperfection and minimizes the drug expulsion. The homogeneous S-NLCs with narrow particle size distribution and suitable ZP (Table 1), preserved their uniformity and spherical shape during the storage (Fig. 1) indicating the suitability of materials and preparation technique. In contrast to SLNs in which the aggregation or perikinetic flocculation may occur during the storage [27-29], the particles in highlyconcentrated NLCs formed a network (Fig. 1b) that may not result in the collision of particles during the long-term storage.

Thermal behaviours of bulk materials, blank NLCs, and S-NLCs were determined by DSC (Fig. 2). The disappearance of sharp endothermic peak of pure sesamol in DSC thermogram of S-NLCs suggests that sesamol is distributed in an amorphous status. Furthermore, the melting peaks of blank- or S-NLCs shifted to the lower temperature indicating that the bulk materials have been transformed into the nanoparticulate forms. Small particle size and enhanced surface of nanopartiocles may also result in the depression of melting point [62]. SNLCs showed lower melting point as compared to the blank NLCs that might be due to the incorporation of sesamol into the lipid matrix.

A hyperbolic trend in the release profile (Fig. 3) indicates the controlled-release pattern of sesamol from NLCs which may be due to the partitioning of sesamol between the lipid and aqueous phases and interactions between the surfactant-lipid or sesamol-lipid molecules. The prolonged release may also be attributed to the diffusion of sesamol from the lipid core of NLCs. This kind of release pattern by providing a constant
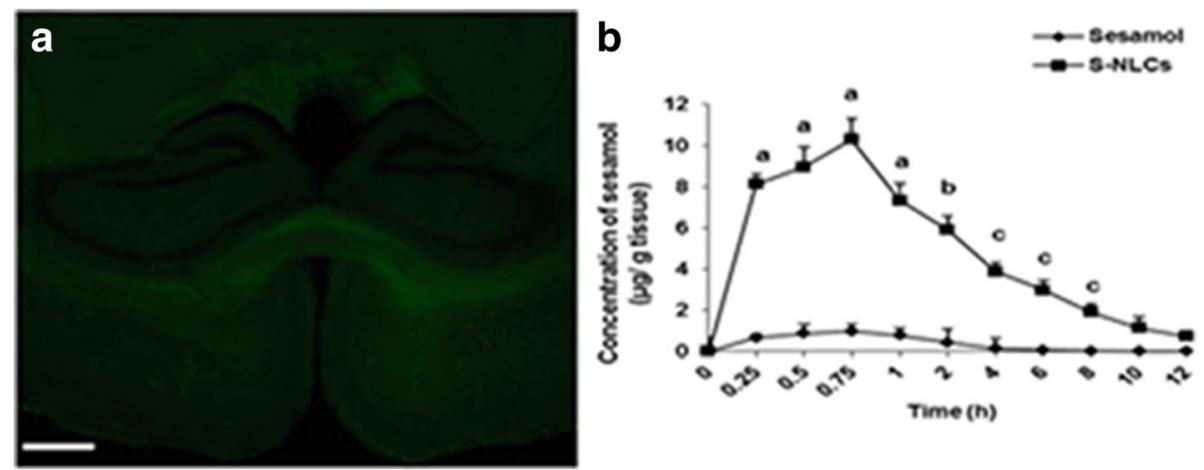

Fig. 7 The brain delivery of S-NLCs. a: The presence of coumarin-6-loaded S-NLCs in the hippocampus which is one of the most vulnerable brain regions in the ischemic stroke (scale bar: $500 \mu \mathrm{m}$ ), $\mathbf{b}$ : Brain distribution study shows that S-NLCs provide significantly higher concentrations of sesamol in the brain. ${ }^{a} P<0.001,{ }^{b} P<0.01$, and ${ }^{c} P<0.05$ vs. sesamol-treated group. (S-NLCs: sesamol-loaded nanostructured lipid carriers) 
Table 4 The effects of sesamol or S-NLCs on I/R-induced neurobehavioral deficits

\begin{tabular}{|c|c|c|c|}
\hline Groups scores & $\begin{array}{l}\text { Neurological } \\
(1-5)\end{array}$ & $\begin{array}{l}\text { MWMT } \\
\text { TSTQ (s) }\end{array}$ & $\begin{array}{l}\text { STPAT } \\
\text { Latency (s) }\end{array}$ \\
\hline $\begin{array}{l}\text { Sham } \\
\text { Intact } \\
\text { I/R } \\
\text { I/R + vehicle } \\
\text { I/R + sesamol }(5 \mathrm{mg} / \mathrm{kg}) \\
\text { I/R + sesamol }(10 \mathrm{mg} / \mathrm{kg}) \\
\text { I/R + sesamol }(20 \mathrm{mg} / \mathrm{kg}) \\
\text { I/R + sesamol }(25 \mathrm{mg} / \mathrm{kg}) \\
\text { I/R + blank NLCs } \\
\text { I/R + S-NLCs }(5 \mathrm{mg} / \mathrm{kg}) \\
\text { I/R + S-NLCs }(10 \mathrm{mg} / \mathrm{kg}) \\
\text { I/R + S-NLCs }(20 \mathrm{mg} / \mathrm{kg}) \\
\text { I/R + S-NLCs }(25 \mathrm{mg} / \mathrm{kg}) \\
\mathrm{LY}+\mathrm{I} / \mathrm{R}+\mathrm{S}-\mathrm{NLCs}(20 \mathrm{mg} / \mathrm{kg}) \\
\mathrm{LY}+\mathrm{I} / \mathrm{R}+\mathrm{S}-\mathrm{NLCs}(25 \mathrm{mg} / \mathrm{kg})\end{array}$ & $\begin{array}{l}0 \\
0 \\
3.84 \pm 0.36^{a} \\
3.67 \pm 0.44^{a} \\
3.44 \pm 0.49^{a} \\
3.52 \pm 0.23^{a} \\
3.74 \pm 0.38^{a} \\
2.98 \pm 0.29^{a} \\
4.03 \pm 0.26^{a} \\
3.57 \pm 0.22^{a} \\
3.28 \pm 0.17^{a} \\
1.76 \pm 0.13^{b} \\
1.27 \pm 0.07^{c} \\
3.55 \pm 0.47^{a} \\
3.21 \pm 0.29^{a}\end{array}$ & $\begin{array}{l}75.38 \pm 6.26 \\
77.21 \pm 4.23 \\
16.33 \pm 1.14^{\mathrm{a}} \\
14.83 \pm 0.79^{\mathrm{a}} \\
17.66 \pm 1.02^{\mathrm{a}} \\
15.79 \pm 0.76^{\mathrm{a}} \\
19.49 \pm 1.31^{\mathrm{a}} \\
16.65 \pm 1.27^{\mathrm{a}} \\
18.33 \pm 0.62^{\mathrm{a}} \\
26.42 \pm 2.41^{\mathrm{a}} \\
23.79 \pm 2.29^{\mathrm{a}} \\
59.61 \pm 3.76^{\mathrm{d}} \\
66.27 \pm 4.33^{\mathrm{c}} \\
18.43 \pm 1.75^{\mathrm{a}} \\
16.77 \pm 2.93^{\mathrm{a}}\end{array}$ & $\begin{array}{l}283.17 \pm 10.69 \\
278.42 \pm 12.18 \\
179.11 \pm 9.46^{a} \\
184.40 \pm 11.32^{a} \\
176.61 \pm 7.47^{a} \\
185.63 \pm 11.33^{a} \\
183.57 \pm 9.97^{a} \\
195.46 \pm 12.68^{a} \\
173.77 \pm 7.63^{a} \\
189.27 \pm 16.54^{a} \\
177.11 \pm 11.13^{a} \\
217.50 \pm 9.56^{a} \\
237.33 \pm 13.10^{c} \\
180.16 \pm 9.76^{a} \\
191.45 \pm 12.37^{a}\end{array}$ \\
\hline
\end{tabular}

S-NLCs, but not free sesamol, significantly attenuated the neurobehavioral deficits induced by global ischemia. Data are presented as mean \pm SEM ( $n=6$ ) (I/R ischemia/reperfusion, S-NLCs sesamol-loaded nanostructured lipid carriers, LY LY294002 (25 $\mathrm{gg} / \mu \mathrm{l})$, MWMT Morris water maze test, TSTQ time spent in target quadrant, STPAT: step-through passive avoidance test, latency; time spent in crossing from the illuminated to the darkened compartment)

${ }^{a} P<0.001$ vs. sham or intact, ${ }^{b} P<0.01$ vs. sham, intact, $I / R$, or $I / R+$ vehicle, ${ }^{c} P<0.001$ vs. $I / R$ or $I / R+$ vehicle, ${ }^{d} P<0.01$ vs. sham or intact and $P<0.001$ vs. $I / R$ or $I /$ $\mathrm{R}+$ vehicle, ${ }^{\mathrm{e}} \mathrm{P}<0.05 \mathrm{vs}$. $\mathrm{l} / \mathrm{R}$ or $\mathrm{I} / \mathrm{R}+$ vehicle

concentration of sesamol for longer time period might be of therapeutic value.

Since the cell internalization of nanoparticles is highly influenced by their size and surface properties, we selected S-NLCs7 as the optimal formulation due to the suitable EE\%, DL\%, and particle size (Table 1). These types of nanoparticles with particle diameter less than $100 \mathrm{~nm}$ and large surface area have shown unique biological effects such as the ability to bypass the reticuloendothelial system. Furthermore, the probability of destruction or phagocytosis is minimized [27-29] that may result in the enhanced retention time and efficiency. In this respect, these nanoparticles have been suggested as suitable carriers for effective drug delivery into the brain [27]. Regarding the bioactivity of S-NLCs in an in vitro model of ischemic stroke, MTT assay revealed that SNLCs, but not free sesamol, exert dose-dependent protective effects in longer exposure to OGD/R (Fig. 4) indicating the ability of this nanocarrier to provide a sustained concentration of sesamol. The cellular damage was also evaluated by measuring an indicator of cell toxicity, $\mathrm{LDH}$, the cytoplasmic enzyme which is rapidly released into the cell culture medium following the damage of cell plasma membrane. In general, increased $\mathrm{LDH}$ activity has been recognized as a marker for the ischemic processes or cell death [39]. As shown in Fig. 5, sesamol solution failed to prevent the enhancement of LDH due to 8-h OGD, while, S-NLCs showed efficiency at both 1 - and 8-h OGD indicating the ability of this nanocompound to protect sesamol against the rapid metabolism leading to the prolonged protective effects.

Unlike the free sesamol, S-NLCs protected PC12 cells, a model of neuron-like cells, against the morphological alterations due to 8-h OGD (Fig. 6) indicating the prolonged
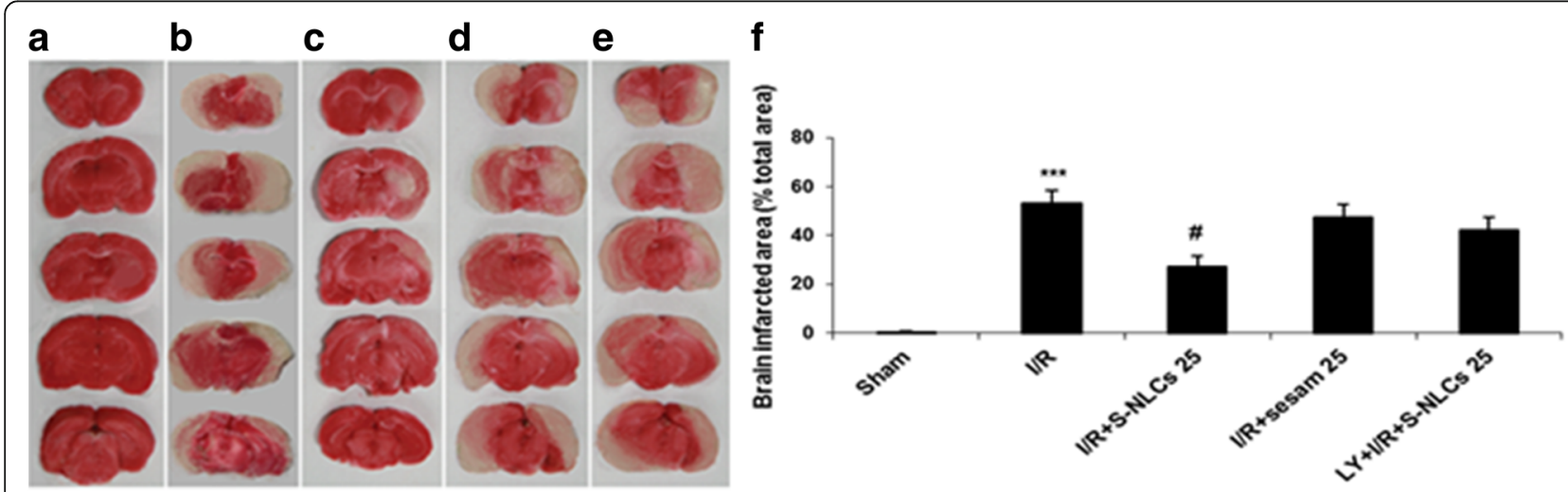

Fig. 8 Representative photographs of brain coronal sections stained with TTC. a: sham, b: I/R (infarcted areas have been shown in white), c: S-NLCs

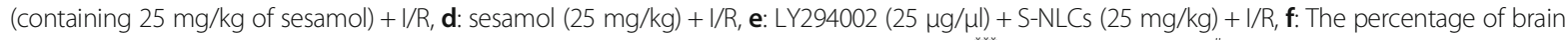
infarcted area with respect to the total area. Data are represented as mean \pm SEM $(n=6)$. ${ }^{* *} P<0.001$ vs. sham, ${ }^{\#} P<0.01$ vs. I/R group. (TTC: $2,3,5-$ triphenyltetrazolium chloride, I/R: ischemia/reperfusion, LY: LY294002, S-NLCs: sesamol-loaded nanostructured lipid carriers) 

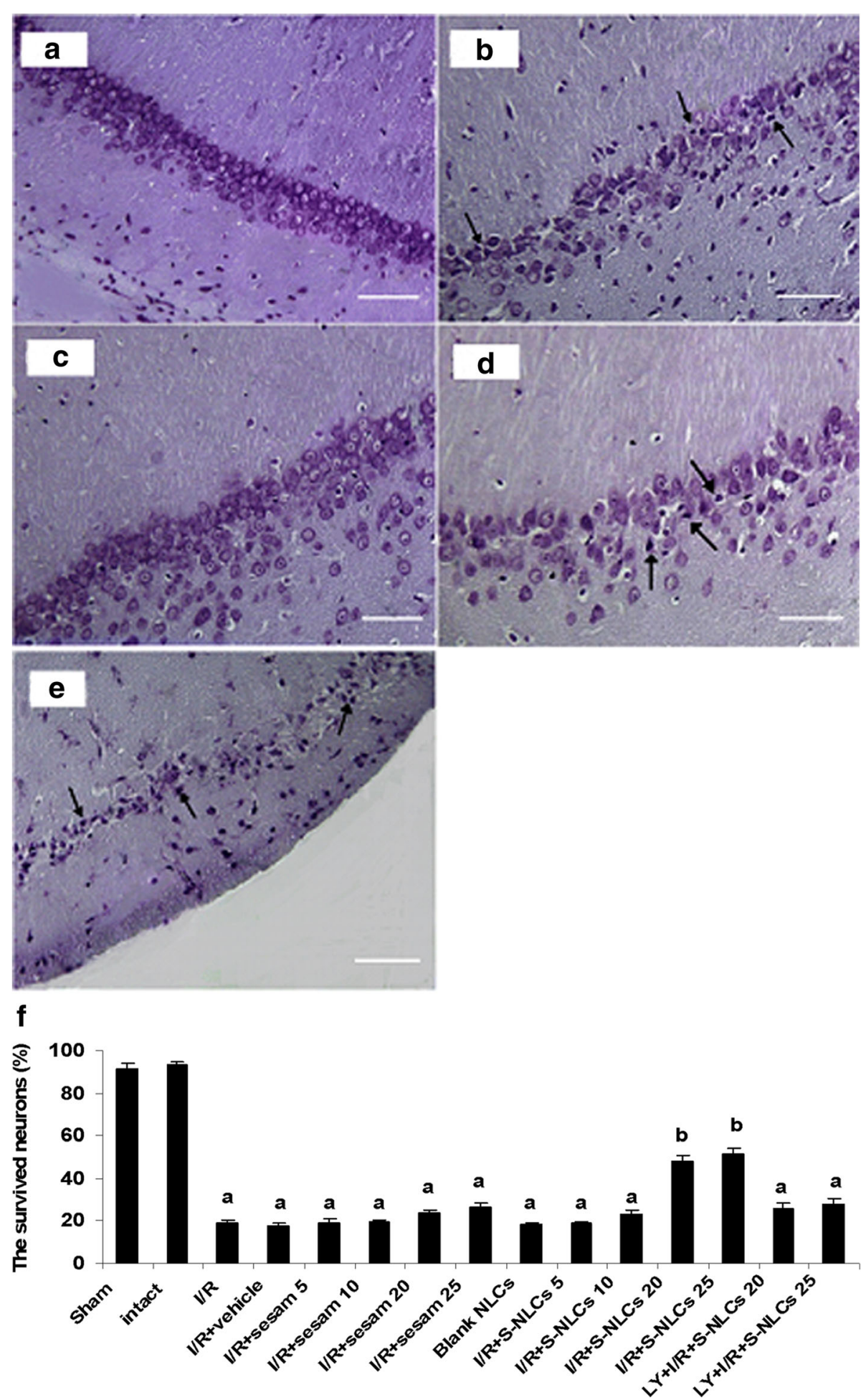

Fig. 9 (See legend on next page.) 
(See figure on previous page.)

Fig. 9 Representative photomicrographs of hippocampal slices and quantitative analysis of the survived neurons in CA1 sub-regions. a: The viable round cells with distinct nucleus and nucleolus in sham-operated group, $\mathbf{b}$ : Dark-stained cells with dysmorphic or shrunken shape (black arrows) due to 10-min ischemia followed by $72 \mathrm{~h}$ reperfusion, c: Treatment with S-NLCs (containing $25 \mathrm{mg} / \mathrm{kg}$ of sesamol) attenuated I/R-induced neuronal damage, d: Free sesamol (25 mg/kg) failed to effectively prevent I/R-induced neuronal injury, e: Pre-treatment with LY294002 (25 $\mu \mathrm{m} / \mu \mathrm{l})$ abolished the ameliorative effects of S-NLCs (25 mg/kg), (scale bars: $50 \mu \mathrm{m})$. f: S-NLCs (20 and $25 \mathrm{mg} / \mathrm{kg}$ ), but not sesamol, significantly increased the survived neurons in the hippocampal CA1 region. Pre-treatment with LY294002 $(25 \mu \mathrm{g} / \mu \mathrm{l})$ prevented the neuroprotective effects of S-NLCs. Data are expressed as mean \pm SEM $(n=6){ }^{a} P<0.001$ vs. sham or intact group, ${ }^{b} P<0.001$ vs. sham, intact, I/R or I/R + vehicle groups. (I/R: ischemia/reperfusion, LY: LY294002, S-NLCs: sesamol-loaded nanostructured lipid carriers)

therapeutic effect of S-NLCs. As shown in Table 3, SNLCs, but not sesamol, dose-dependently suppressed 8-h OGD-induced oxidative stress as revealed by the ability of this nanocarrier to reduce the production of MDA, an indicator of free radical generation, oxidative stress, and tissue injury [63], and enhance the content of GSH, a free radical scavenger and an essential component of cellular defence mechanism against the oxidative stress [64], and activities of SOD, an essential enzyme for the removal of superoxide radicals and protecting the cells against the oxidative injury [65], and CAT which is responsible for degradation of $\mathrm{H}_{2} \mathrm{O}_{2}$ and protects the cells against the oxidative stress [66]. These findings indicate the ability of NLCs to provide longer-lasting effects for sesamol. Based on the protective effects of sesamol against the neuronal injury $[6-8,11-13,67]$, the extended activity of this phenolic compound might be of therapeutic significance against the cellular dysfunction in the acute or chronic forms of neural injury.

Besides the application of the visualization technique and brain distribution study (Fig. 7), evaluation of the bioactivity of S-NLCs in an in vivo model of ischemic strike confirmed the successful delivery of these nanoparticles into the rat brain. As shown in Table 4 and Fig. 8, S-NLCs effectively prevented I/R-induced neurobehavioral deficits.
S-NLCs, but not free sesamol, significantly attenuated I/Rinduced histopathological alterations and cell loss in the CA1 hippocampal region (Fig. 9) which is one of the most vulnerable brain regions in the cerebral ischemia [68]. Even after a few minutes of global brain ischemia, the pyramidal cells of CA1 sub-region become irreversibly damaged $[68,69]$. Therefore, S-NLCs by providing sustained concentrations of sesamol might be of therapeutic value in $\mathrm{I} / \mathrm{R}$-induced neuronal injury.

Because of its high rate of oxidative metabolic activity, brain is one of the most vulnerable tissues to the oxidative stress [69]. Antioxidant enzymes including the SOD and CAT by eliminating the free radicals protect the brain against the ischemic insult [70]. Furthermore, GSH which is involved in the maintenance of cell integrity, serves as a primary defensive agent against the oxidative stress in the brain $[7,65]$. In this respect, S-NLCs by potentiating the antioxidant defense system and attenuation of I/R-induced oxidative stress in the hippocampal region (Table 5) may exert promising neuroprotective effects. Indeed, NLC-based formulations are promising therapeutic candidates against a variety of pathological conditions including the ophthalmic disorders [71, 72].

Sesamol even at the highest dose tested failed to significantly affect I/R-induced neurobehavioral deficits and

Table 5 Effects of sesamol or S-NLCS on the biochemical parameters in hippocampus following the global ischemia

\begin{tabular}{|c|c|c|c|c|}
\hline Groups & $\begin{array}{l}\text { MDA } \\
\text { (nM/mg protein) }\end{array}$ & $\begin{array}{l}\text { GSH } \\
\text { (nM/mg protein) }\end{array}$ & $\begin{array}{l}\text { SOD } \\
\text { (U/mg protein) }\end{array}$ & $\begin{array}{l}\text { CAT } \\
\text { (U/mg protein) }\end{array}$ \\
\hline Sham & $0.92 \pm 0.06$ & $1.98 \pm 0.09$ & $5.77 \pm 0.25$ & $4.69 \pm 0.32$ \\
\hline Intact & $0.87 \pm 0.09$ & $2.02 \pm 0.18$ & $5.83 \pm 0.19$ & $4.58 \pm 0.54$ \\
\hline I/R & $2.12 \pm 0.21^{* *}$ & $0.96 \pm 0.22^{* * *}$ & $3.31 \pm 0.13^{* * *}$ & $2.49 \pm 0.17^{* * *}$ \\
\hline l/R + vehicle & $2.16 \pm 0.19^{* *}$ & $0.91 \pm 0.15^{* * *}$ & $3.24 \pm 0.21^{* * *}$ & $2.55 \pm 0.22^{* * *}$ \\
\hline $\mathrm{l} / \mathrm{R}+$ sesamol $(5 \mathrm{mg} / \mathrm{kg})$ & $2.09 \pm 0.20^{* *}$ & $0.98 \pm 0.17^{* *}$ & $3.13 \pm 0.15^{* * *}$ & $2.63 \pm 0.24^{* * *}$ \\
\hline $\mathrm{l} / \mathrm{R}+\operatorname{ses} a \mathrm{~mol}(10 \mathrm{mg} / \mathrm{kg})$ & $2.23 \pm 0.18^{* *}$ & $0.87 \pm 0.15^{* * *}$ & $3.68 \pm 0.25^{* * *}$ & $2.68 \pm 0.18^{* * *}$ \\
\hline $\mathrm{l} / \mathrm{R}+$ sesamol $(20 \mathrm{mg} / \mathrm{kg})$ & $1.93 \pm 0.20^{*}$ & $1.04 \pm 0.06^{* *}$ & $3.60 \pm 0.37^{* * *}$ & $2.77 \pm 0.12^{* * *}$ \\
\hline $\mathrm{l} / \mathrm{R}+$ sesamol $(25 \mathrm{mg} / \mathrm{kg})$ & $1.84 \pm 0.19^{*}$ & $1.09 \pm 0.13^{* *}$ & $3.79 \pm 0.19^{* * *}$ & $2.61 \pm 0.15^{* * *}$ \\
\hline I/R + blank NLCs & $2.03 \pm 0.34^{*}$ & $1.01 \pm 0.19^{* *}$ & $3.31 \pm 0.11^{* * *}$ & $2.83 \pm 0.25^{* * *}$ \\
\hline $\mathrm{l} / \mathrm{R}+\mathrm{S}-\mathrm{NLCs}(5 \mathrm{mg} / \mathrm{kg})$ & $2.14 \pm 0.24^{* *}$ & $0.98 \pm 0.15^{* *}$ & $3.19 \pm 0.20^{* * *}$ & $2.80 \pm 0.16^{* * *}$ \\
\hline $\mathrm{I} / \mathrm{R}+\mathrm{S}-\mathrm{NLCs}(10 \mathrm{mg} / \mathrm{kg})$ & $1.95 \pm 0.15^{*}$ & $0.93 \pm 0.24^{* * *}$ & $2.77 \pm 0.23^{* * *}$ & $3.13 \pm 0.14^{* *}$ \\
\hline $\mathrm{l} / \mathrm{R}+\mathrm{S}-\mathrm{NLCs}(20 \mathrm{mg} / \mathrm{kg})$ & $1.29 \pm 0.15^{\Omega}$ & $1.63 \pm 0.09^{\ngtr}$ & $4.68 \pm 0.19^{\Delta}$ & $4.06 \pm 0.29^{\Phi}$ \\
\hline $\mathrm{I} / \mathrm{R}+\mathrm{S}-\mathrm{NLCs}(25 \mathrm{mg} / \mathrm{kg})$ & $1.08 \pm 0.12^{\#}$ & $1.81 \pm 0.07^{\Sigma}$ & $4.97 \pm 0.14^{£}$ & $4.29 \pm 0.12^{€}$ \\
\hline$L Y+I / R+S-N L C s(20 \mathrm{mg} / \mathrm{kg})$ & $2.13 \pm 0.16^{* *}$ & $0.93 \pm 0.13^{* * *}$ & $3.07 \pm 0.24^{* *}$ & $2.66 \pm 0.19^{* * *}$ \\
\hline$L Y+I / R+S-N L C s(25$ mg/kg) & $1.99 \pm 0.22^{*}$ & $1.07 \pm 0.09^{* *}$ & $3.16 \pm 0.11^{* * *}$ & $2.37 \pm 0.98^{* * *}$ \\
\hline
\end{tabular}

S-NLCs, but not free sesamol, significantly attenuated the oxidative stress induced by the global ischemia. Data are presented as mean \pm SEM ( $n=6$ ) (I/R ischemia/reperfusion, NLCs nanostructured lipid carriers, S-NLCS sesamol-loaded NLCs, MDA malondialdehyde, GSH reduced glutathione, SOD superoxide dismutase, CAT catalase)

${ }^{*} \mathrm{P}<0.05,{ }^{* *} P<0.01,{ }^{* * *} P<0.001$ vs. sham or intact, ${ }^{¥} \mathrm{P}<0.05,{ }^{\Phi}, \Delta, \Omega, \#, \Sigma \in \mathrm{P}<0.01,{ }^{\mathrm{f}} \mathrm{P}<0.001$ vs. $\mathrm{l} / \mathrm{R}$ or $\mathrm{I} / \mathrm{R}+\mathrm{vehicle}$ 
oxidative stress (Figs 8 and 9, Tables 4 and 5) that might be due to the rapid metabolism and/or limited number of injections leading to the subtherapeutic concentrations in brain. In previous reports, sesamol has shown efficiency following 14-21 daily injections [9, 11, 12], while, in the present study, S-NLCs following the limited number of injections exhibited therapeutic effects indicating the enhanced bioavailability and efficiency of sesamol following its incorporation into the NLCs. Application of LY294002 abrogated the protective effects of S-NLCs (Figs. 4-6, 8 and 9, Tables 3-5) indicating that SNLCs, like the classical neuroprotective agents, are able to recruit PI3K signalling pathway.

\section{Conclusions}

NLCs serve as promising carriers for sesamol, a phenolic compound with a wide spectrum of pharmacological activities. S-NLCs by improving the pharmacological profile of sesamol provide longer-lasting therapeutic effects in both in vitro and in vivo models of stroke. This nanoformulation through the activation of PI3K pathway might be a suitable controlled release drug carrier system against the ischemic injuries or other neurodegenerative pathologies.

\begin{abstract}
Abbreviations
CAT: Catalase; DL: Drug loading; DMSO: Dimethyl sulfoxide; DSC: Differential scanning calorimetry; EE: Entrapment efficiency; GSH: Reduced glutathione; HPLC: High-performance liquid chromatography; I/R: Ischemia/reperfusion; LDH: Lactate dehydrogenase; MDA: Malondialdehyde; MTT: 3-[4,5dimethylthiazol-2-yl]-2,5-diphenyl tetrazolium bromide; MWM: Morris watermaze; OGD: Oxygen-glucose deprivation; PBS: Phosphate buffered saline; PDI: Polydispersity index; PI3K: Phosphatidylinositol 3-kinase; S-

NLCs: Sesamol-loaded nanostructured lipid carriers; SOD: Superoxide dismutase; STPAT: Step-through passive avoidance test; TBA: Thiobarbituric acid; TC: 2,3,5-triphenyltetrazolium chloride; ZP: Zeta potential
\end{abstract}

\section{Acknowledgements}

Authors would like to thank Mrs. Faezeh Khosravi for technical assistance.

\section{Funding}

This research did not receive any specific grant from funding agencies in the public, commercial, or not-for-profit sectors.

\section{Availability of data and materials}

Available upon the request.

\section{Authors' contributions}

FA, the chief instructor of the experiment, and PH performed the experiments, interpreted the data, and wrote the first draft of the manuscript. Other authors contributed to the experimental procedures. All authors read and approved the final manuscript.

\section{Ethics approval}

The protocol for the in vivo experiments has been approved by the Institutional Animal Care and Use Committee.

\section{Consent for publication}

Not applicable

\section{Competing interests}

The authors declare that they have no competing interests.

\section{Publisher's Note}

Springer Nature remains neutral with regard to jurisdictional claims in published maps and institutional affiliations.

\section{Author details}

${ }^{1}$ Nanotechnology Research Center, Faculty of Pharmacy, Tehran University of Medical Sciences, Tehran, Iran. ${ }^{2}$ Department of Pharmaceutics, Faculty of Pharmacy, Tehran University of Medical Sciences, Tehran, Iran. ${ }^{3}$ Department of Pharmacology, Faculty of Medicine, Tehran University of Medical Sciences, Tehran, Iran.

Received: 13 September 2017 Accepted: 1 December 2017

Published online: 20 December 2017

\section{References}

1. Klijn CJ, Hankey GJ. Management of acute ischaemic stroke: new guidelines from the American Stroke Association and European stroke initiative. Lancet Neurol. 2003;2:698-701.

2. Moskowitz MA, Lo EH, ladecola C. The science of stroke: mechanisms in search of treatments. Neuron. 2010;67:181-98.

3. Serteser M, Ozben T, Gumuslu S, Balkan S, Balkan E. The effects of NMDA receptor antagonist MK-801 on lipid peroxidation during focal cerebral ischemia in rats. Prog Neuro-Psychopharmacol Biol Psychiatry. 2002;26:871-7.

4. Xu L, Sun J, Lu R, Ji Q, Xu JG. Effect of glutamate on inflammatory responses of intestine and brain after focal cerebral ischemia. World J Gastroenterol. 2005;11:733-6.

5. Chen H, Yoshioka H, Kim GS, Jung JE, Okami N, Sakata H, et al. Oxidative stress in ischemic brain damage: mechanisms of cell death and potential molecular targets for neuroprotection. Antioxid Redox Signal. 2011;14:1505-17.

6. Wu XL, Liou CJ, Li ZY, Lai XY, Fang LW, Huang WC. Sesamol suppresses the inflammatory response by inhibiting NF-KB/MAPK activation and upregulating AMP kinase signaling in RAW 264.7 macrophages. Inflamm Res. 2015;64:577-88,

7. Kumar $\mathrm{P}$, Kalonia $\mathrm{H}$, Kumar A. Protective effect of sesamol against 3nitropropionic acid-induced cognitive dysfunction and altered glutathione redox balance in rats. Basic Clin Pharmacol Toxicol. 2010;107:577-82.

8. Sharma S, Kaur IP. Development and evaluation of sesamol as an antiaging agent. Int J Dermatol. 2006;45:200-8.

9. Kumar B, Kuhad A, Chopra K. Neuropharmacological effect of sesamol in unpredictable chronic mild stress model of depression: behavioral and biochemical evidences. Psychopharmacology. 2011;214:819-28.

10. Changa CC, Luc WJ, Chiang CW, Jayakumarc T, Ong ET, Hsiaoc G, et al. Potent antiplatelet activity of sesamol in an in vitro and in vivo model: pivotal roles of cyclic AMP and p38 mitogen-activated protein kinase. J Nutr Biochem. 2010;21:1214-21.

11. Hassanzadeh P. Hassanzadeh A. Implication of NGF and endocannabinoid signalling in the mechanism of action of sesamol: a multi-target natural compound with therapeutic potential. Psychopharmacology. 2013;229:571-8.

12. Hassanzadeh P, Arbabi E, Rostami F. The ameliorative effects of sesamol against seizures, cognitive impairment and oxidative stress in the experimental model of epilepsy. Iran J Basic Med Sci. 2014;17:100-7.

13. Ahmad S, Yousuf S, Ishrat T, Khan MB, Bhatia K, Fazli IS, et al. Effect of dietary sesame oil as antioxidant on brain hippocampus of rat in focal cerebral ischemia. Life Sci. 2005;79:1921-8.

14. Jan $\mathrm{KC}, \mathrm{Ho} C \mathrm{CT}$, Hwang LS. Bioavailability and tissue distribution of sesamol in rat. J Agric Food Chem. 2008;56:7032-7.

15. Geetha T, Singh N, Deol PK, Kaur IP. Biopharmaceutical profiling of sesamol: physiochemical characterization, gastrointestinal permeability and pharmacokinetic evaluation. RSC Adv. 2015;5:4083-91.

16. Hassanzadeh P. New perspectives in biosensor technology. Gastroenterol Hepatol Bed Bench. 2010;3:105-7.

17. Hassanzadeh P, Fullwood I, Sothi S, Aldulaimi D. Cancer nanotechnology. Gastroenterol Hepatol Bed Bench. 2011;4:63-9.

18. Hassanzadeh P. Nanopharmaceurticals: innovative theranostics for the neurological disorders. Biomed Rev. 2014;25:25-34.

19. Hassanzadeh P, Arbabi E, Rostami F, Atyabi F, Dinarvand R. Carbon nanotubes prolong the regulatory action of nerve growth factor on the endocannabinoid signaling. Physiol Pharmacol. 2015;19:167-76.

20. Hassanzadeh P, Arbabi P, Atyabi F, Dinarvand R. Carbon nanotubeanandamide complex exhibits sustained protective effects in an in vitro model of stroke. Physiol Pharmacol. 2016;20:12-23. 
21. Hassanzadeh P, Arbabi P, Atyabi F, Dinarvand R. Application of carbon nanotubes as the carriers of the cannabinoid, 2-arachidonoylglycerol: towards a novel treatment strategy in colitis. Life Sci. 2017;179:66-72.

22. Hassanzadeh P, Arbabi P, Atyabi F, Dinarvand R. Nerve growth factor-carbon nanotube complex exerts prolonged protective effects in an in vitro model of ischemic stroke. Life Sci. 2017;179:15-22.

23. Hassanzadeh P, Atyabi F, Dinarvand R. Application of carbon nanotubes for controlled release of growth factors or endocannabinoids: a breakthrough in biomedicine. Biomed Rev. 2016;27:19-27.

24. Kim D, Chun BG, Kim YK, Lee YH, Park CS, Jeon I, et al. In vivo tracking of human mesenchymal stem cells in experimental stroke. Cell Transplant. 2008;16:1007-12.

25. Marsh JN, Hu G, Scot MJ, Zhang H, Goette MJ, Gaffney PJ, et al. A fibrinspecific thrombolytic nanomedicine approach to acute ischemic stroke. Int J Nanomedicine. 2012;7:5137-49.

26. Ghosh A, Sarkar S, Mandal AK, Das N. Neuroprotective role of nanoencapsulated quercetin in combating ischemia-reperfusion induced neuronal damage in young and aged rats. PLoS One. 2013:8:e57735.

27. Müller RH. Lipid nanoparticles: recent advances. Adv Drug Deliv Rev. 2007; 59:375-6.

28. Müller RH, Rühl D, Runge S, Schulze-Forster K, Mehnert W. Cytotoxicity of solid lipid nanoparticles as a function of the lipid matrix and the surfactant. Pharm Res. 1997;14:458-62.

29. Freitas C, Müller RH. Correlation between long-term stability of solid lipid nanoparticles (SLNs) and crystallinity of the lipid phase. Eur J Pharm Biopharm. 1999;47:125-32.

30. Li F, Wang WYL, He H, Yang J, Tang X. The efficacy and safety of bufadienolides loaded nanostructured lipid carriers. Int J Pharm. 2010;393:203-11.

31. Kumbhar DD, Pokharkar VB. Engineering of a nanostructured lipid carrier for the poorly water-soluble drug, bicalutamide: physicochemical investigations. Colloids Surf A Physicochem Eng Asp. 2013:416:32-42.

32. Cantley LC. The phosphoinositide 3-kinase pathway. Science. 2002;296:1655-7.

33. Mullonkal CJ, Toledo-Pereyra LH. Akt in ischemia and reperfusion. J Investig Surg. 2007;20:195-203.

34. Beloqui A, Solinís MÁ, Gascón AR, del Pozo-Rodríguez A, des Rieux A, Préat $\checkmark$. Mechanism of transport of saquinavir-loaded nanostructured lipid carriers across the intestinal barrier. J Control Release. 2013:166:115-23.

35. Yang R, Zhang S, Kong D, Gao X, Zhao Y, Wang Z. Biodegradable polymercurcumin conjugate micelles enhance the loading and delivery of low potency curcumin. Pharm Res. 2012;29:3512e25.

36. Mehta SL, Manhas N, Raghubir R. Molecular targets in cerebral ischemia for developing novel therapeutics. Brain Res Rev. 2007;54:34-66.

37. Larsen EC, Hatcher JF, Adibhatla RM. Effect of tricyclodecan-9-yl potassium xanthate (D609) on phospholipid metabolism and cell death during oxygen-glucose deprivation in PC12 cells. Neuroscience. 2007;146:946-61.

38. Koha SH, Kwon H, Parka KH, Ko JK, Kim JH, et al. Protective effect of diallyl disulfide on oxidative stress-injured neuronally differentiated PC12 cells. Mol Brain Res. 2005:133:176-86.

39. Zakharova IO, Sokolova TV, Bayunova LV, Vlasova YA. a-Tocopherol at nanomolar concentration protects PC12 cells from hydrogen peroxide-induced death and modulates protein kinase activities. Int J Mol Sci. 2012;13:11543-68.

40. Carmichael J, DeGraff WG, Gazdar AF, Minna JD, Mitchell JB. Evaluation of a tetrazolium-based semiautomated colorimetric assay: assessment of chemosensitivity testing. Cancer Res. 1987:47:936-41.

41. Decker T, Lohmann-Matthes ML. A quick and simple method for the quantitation of lactate dehydrogenase release in measurements of cellular cytotoxicity and tumor necrosis factor (TNF) activity. J Immunol Methods. 1988;115:61-9.

42. Zhao J, Bai Y, Zhang C, Zhang X, Zhang YX, Chen J, et al. Cinepazide maleate protects PC12 cells against oxygen-glucose deprivation-induced injury. Neurol Sci. 2014;35:875-81.

43. Bradford MM. A rapid and sensitive method for the quantitation of microgram quantities of protein utilizing the principle of protein-dye binding. Anal Biochem. 1976;72:248-54

44. Ohkawa H, Ohishi N, Yagi K. Assay for lipid peroxides in animal tissues by thiobarbituric acid reaction. Anal Biochem. 1979:95:351-8.

45. Jollow DJ, Mitchell JR, Zampaglione N, Gillette JR. Bromobenze induced liver necrosis: protective role of glutathione and evidence for 3,4bromobenzenoxide as the hepatotoxic intermediate. Pharmacology. 1974;11:151-69.

46. Kakkar P, Das B, Viswanathan PN. A modified spectrophotometric assay of superoxide dismutase. Ind J Biochem Biophys. 1984:21:130-2.

47. Aebi H. Catalase in vitro. Methods Enzymol. 1984;105:121-6.
48. Zhaoa C, Fana T, Yanga Y, Wua M, Li L, Zhoua Z, et al. Preparation, macrophages targeting delivery and anti-inflammatory study of pentapeptide grafted nanostructured lipid carriers. Int J Pharm. 2013;450:11-20.

49. Wang $M T$, Jin $Y$, Yang $Y X$, Zhao $C Y$, Yang HY, Xu XF, et al. In vivo biodistribution, anti-inflammatory, and hepatoprotective effects of liver targeting dexamethasone acetate loaded nanostructured lipid carrier system. Int J Nanomedicine. 2010;5:487-97.

50. Pulsinelli WA, Brierley JB. A new model of bilateral hemispheric ischemia in the unanesthetized rat. Stroke. 1979;10:267-72.

51. Hu X, Xie C, He S, Zhang Y, Li Y, Jiang L. Remifentanil postconditioning improves global cerebral ischemia induced spatial learning and memory deficit in rats via inhibition of neuronal apoptosis through the PI3K signaling pathway. Neurol Sci. 2013;34:1955-62.

52. Zhang R, Yang G, Wang Q, Guo F, Wang H. Acylated ghrelin protects hippocampal neurons in pilocarpine-induced seizures of immature rats by inhibiting cell apoptosis. Mol Biol Rep. 2013;40:51-8.

53. Longa EZ, Weinstein PR, Carlson S, Cummins R. Reversible middle cerebral artery occlusion without craniectomy in rats. Stroke. 1989;20:84-91.

54. Morris R. Developments of a water-maze procedure form studying spatial learning in the rat. J Neurosci Methods. 1984;11:47-60.

55. Goldlust EJ, Paczynski RP, He YY, Hsu CY, Goldberg MP. Automated measurement of infarct size with scanned images of triphenyltetrazolium chloride-stained rat brains. Stroke. 1996;27:1657-62.

56. Zhang W, Miao Y, Zhou S, Jiang J, Luo Q, Qiu Y. Neuroprotective effects of ischemic postconditioning on global brain ischemia in rats through upregulation of hippocampal glutamine synthetase. J Clin Neurosci. 2011;18:685-9.

57. Paxinos $G$, Watson $C$. The rat brain in stereotaxic coordinates. San Diego: Academic; 2007.

58. Habauzit V, Morand C. Evidence for a protective effect of polyphenolscontaining foods on cardiovascular health: An update for clinicians. Ther Adv Chronic Dis. 2011:3:87-106.

59. Hassanzadeh P, Atyabi F, Dinarvand R. Resvertrol: more than a phytochemical. Biomed Rev. 2015:26:13-21.

60. Hassanzadeh P, Arbabi E, Atyabi F, Dinarvand R. The endocannabinoid system and NGF are involved in the mechanism of action of resveratrol: a multi-target nutraceutical with therapeutic potential in neuropsychiatric disorders. Psychopharmacology. 2016:233:1087-96.

61. Manach C, Williamson G, Morand G, Scalbert A, Rémésy C. Bioavailability and bioefficacy of polyphenols in humans. I. Review of 97 bioavailability studies. Am J Clin Nut. 2005;81:230S-42S.

62. Siekmann B, Westesen $\mathrm{K}$. Thermoanalysis of the recrystallization process of melt-homogenized glyceride nanoparticles. Colloids Surf B: Biointerfaces. 1994;3:159-75.

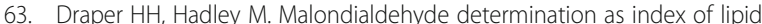
peroxidation. Methods Enzymol. 1990;186:421-31.

64. Spitz DR, Sullivan SJ, Malcolm RR, Roberts RJ. Glutathione dependent metabolism and detoxification of 4-hydroxy-2-nonenal. Free Radic Biol Med. 1991;11:415-23.

65. Warner DS, Sheng $H$, Batinic-Haberle I. Oxidants, antioxidants and the ischemic brain. J Exp Biol. 2004;207:3221-31.

66. Michiels $\mathrm{C}$, Raes M, Toussaint $\mathrm{O}$, Remacle J. Importance of glutathione peroxidase, catalase, and $\mathrm{cu} / \mathrm{Zn}-\mathrm{SOD}$ for cell survival against oxidative stress. Free Radic Biol Med. 1994;17:235-48.

67. Chopra K, Tiwari V, Arora V, Kuhad A. Sesamol suppresses neuro-inflammatory cascade in experimental model of diabetic neuropathy. J Pain. 2010;11:950-7.

68. Schmidt-Kastner R, Freund TF. Selective vulnerability of the hippocampus in brain ischemia. Neuroscience. 1991;4:599-636.

69. White BC, Sullivan JM, DeGracia DJ, O'Neil BJ, Neumar RW, Grossman LI, et al. Brain ischemia and reperfusion: molecular mechanisms of neuronal injury. J Neurol Sci. 2000;179:1-33.

70. Cui K, Luo X, Xu K, Murthy MRV. Role of oxidative stress in neurodegeneration: recent developments in assay methods for oxidative stress and nutraceutical antioxidants. Prog NeuroPsychopharm Biol Psych. 2004;28:771-99.

71. Balguri SP, Adelli GR, Majumdar S. Topical ophthalmic lipid nanoparticle formulations (SLN, NLC) of indomethacin for delivery to the posterior segment ocular tissues. Eur J Pharm Biopharm. 2016;109:224-35.

72. Balguri SP, Adelli GR, Janga KY, Bhagav P, Majumdar S. Ocular disposition of ciprofloxacin from topical, PEGylated nanostructured lipid carriers: effect of molecular weight and density of poly (ethylene) glycol. Int J Pharm. 2017:529:32-43. 